\title{
2D nonlinear site response analysis of shallow bedrock sites using integrated subsurface profiles
}

\author{
Deepu Chandran ${ }^{1}$, Panjamani Anbazhagan*,1 \\ (1) Department of Civil engineering, Indian Institute of Science, Bangalore, India
}

Article history: received May 27, 2019; accepted January 24, 2020

\begin{abstract}
In this study, an attempt has been made to generate the subsurface profiles using integrated geophysical approach and a site-specific 2-D nonlinear site response analysis at shallow bedrock sites in Peninsular India. The site selected for the study is Tarapur, India in which three survey lines were selected for the sub-surface mapping. The subsurface profiling of these three locations was done by an integrated geophysical approach by carrying out Multichannel Analysis of Surface Waves - 2D survey, Ground Penetrating Radar survey, and conventional drilling borehole and measurement of Standard Penetration Test $\mathrm{N}$ values. Thirteen intraplate recordings from all around the world are selected for the site response analysis. The subsurface profiles generated by the integrated geophysical approaches are modeled in FLAC - 2D nonlinear module and site response parameters are estimated. Further 1D site response analyses are carried out at selected points in 2D profiles using the program DEEPSOIL and the 2D site response results are compared. Results of site response analysis are expressed in terms of short-period amplification factor $(\mathrm{Fc})$ and long period amplification factor $(\mathrm{Fs})$ and the results show that the 2D geometry of sub-surface is more sensitive to the higher frequency content of ground motion especially for subsurface with more heterogeneities. Also, a parametric study has been done on a synthetic 2D profile to quantitatively evaluate the effect of different ground motion characteristics like amplitude and frequency content on 2D site response analysis. The parametric study shows that underground heterogeneity is very sensitive to the ground motions with high-frequency content and low amplitude.
\end{abstract}

Keywords: Ground motion, site response, sub-surface profile, MASW, GPR.

\section{Introduction}

Earthquakes are one of the most destructive natural events in the world which can cause tremendous damage to the structures. Over the recent years there have been many major earthquakes that have occurred in India-Bhuj (2001; Mw 7.6), Uttarkashi (1991; ML 6.6), Jabalpur (1997; Mw 5.8), Latur (1993; Mw 6.1), Kashmir (2005; Mw 7.6), Chamoli (1999; $M L$ 6.8) and Sikkim (2011; Mw 6.9). Even though for many years Peninsular India was considered as a "stable continental region", earthquakes like Bhuj (2001; Mw 7.6), Koyna (1967; Mw 7.6), Jabalpur (1997; Mw 5.8) and Latur (1993; Mw 6.1) occurred in this 'stable region' are demanding a seismic study at this region. Also, many 


\section{Deepu Chandran et al.}

researchers have noted that the seismic activity of Peninsular India has increased in recent years and cannot be considered as a stable continental region [Anbazhagan et al., 2010; Boominathan et al., 2008; Ganesha Raj and Nijagunappa, 2004]. All these studies are pointing to do a site-specific ground response analysis in Peninsular India especially for the important structures.

Site response analysis is a process of estimating the local site effects due to the ground motion propagation during an earthquake shaking and it became an important step for the geotechnical design of important structures [Roesset, 1977; Idriss, 1990; Kramer, 1996; Borja et al., 2002; Idriss and Seed 1968; Ferraro et al., 2008]. It gives the input for the soil-structure interaction analysis. Generating the representative subsurface profiles is an important step in the site response analysis as it gives the input parameters for the analysis [Panzera et al., 2016]. Most of the site response analyses carried out in Peninsular India are one dimensional [Boominathan et al. 2008; Anbazhagan and Sitharam 2008; Jaya and Remmya 2010; Maheswari et al., 2008], in which the input parameters are obtained through SPT data or MASW 1-D data. These analyses were done with the assumption that the soil layers are uniform which is not completely true due to the heterogeneous soil deposits in the region. Hence these studies may not be very effective for the estimation of the actual site effect due to spatial variation of the subsurface. The application of $2 \mathrm{D}$ or 3D site response could result in better estimation of site response which accounts the effect of spatial variability of the subsurface [Sanchez-Sesma and Luzon 1995; Heymsfield, 2000; Kamiyama and Satoh 2002; Finn et al., 2003; Semblat et al., 2003; Capilleri et al., 2018].

The main objective of this study is to do a detailed subsurface characterization in 2D at selected locations in Peninsular India using integrated geophysical testing and estimate site-specific 2D (Two dimensional) nonlinear site response parameters and compare with 1D result in the same sites. Geophysical surveys such as Ground Penetrating Radar (GPR), Multi-Channel Analysis of Surface Waves (MASW) and conventional geotechnical drilling and Standard Penetration Test (SPT) N measurement are used for the generation of subsurface profiles. GPR and MASW are two commonly used geophysical site investigation techniques [GPR- Gawthorpe et al., 1993; Jol and Bristow, 2003; Moorman et al., 2003; Neal, 2004; Urbini et al., 2001; MASW- Steeples and Miller 1993; Park et al., 1999; Leucci et al., 2007; Maheswari et al., 2008; Anbazhagan and Sitharam, 2009; Mahajan et al., 2007]. The subsurface profiles generated by the integrated geophysical approaches are used for the 2D nonlinear site response analysis by using the programs FLAC 2D. Also, the 2D site response results were compared with conventional 1D site response results using the program DEEPSOIL. These are the two commonly used programs in the field of site response analysis for the last two decades [DEEPSOIL - Hashash and Park, 2001; Phanikanth et al., 2011; Abhishek et al., 2013; FLAC 2D - Movahedasi and Ghayamghamian, 2015; Khanbabazadeh et al., 2016; Rayhani et al., 2007].

\section{Methodology}

The site selected for the study is Tarapur, Palghar district, Maharashtra, India. The location of the site is very near to the sea. Many boreholes were drilled with SPT (Standard Penetration Test) N measurement at the site for proposed construction. Three survey lines were selected at this location for generating the subsurface profiles for the study. The location of the site and the survey lines are shown in Figure 1. The survey lines were selected based on the availability of space and also by connecting multiple boreholes. Geophysical surveys (GPR and MASW) were carried out over these survey lines and data were collected.

GPR is a commonly used geophysical method in the field of subsurface exploration. The identification of different subsurface layers using GPR is mainly depended upon the contrast in the dielectric properties of the materials. The dielectric constant of the material can be determined from the GPR data by knowing the velocity of penetration, depth of material and two-way travel time [Leng and Al-Qadi, 2010] such that

$$
\varepsilon=\left[\frac{\mathrm{ct}}{2 \mathrm{~d}}\right]^{2}
$$

where, $\varepsilon=$ dielectric constant, $\mathrm{c}=$ velocity of light in vacuum $\left(3 \times 10^{8} \mathrm{~m} / \mathrm{s}\right), \mathrm{t}=$ two-way travel time and $\mathrm{d}=\mathrm{depth}$ of investigation. GPR antenna of $25 \mathrm{MHz}$ from MALA geoscience was used in this study. RadExplorer 1.41 software package is used for the GPR data processing. Raw GPR data has undergone different processing routines like time zero adjustment, background removal (which removes the background noise), DC removal (which removes the 


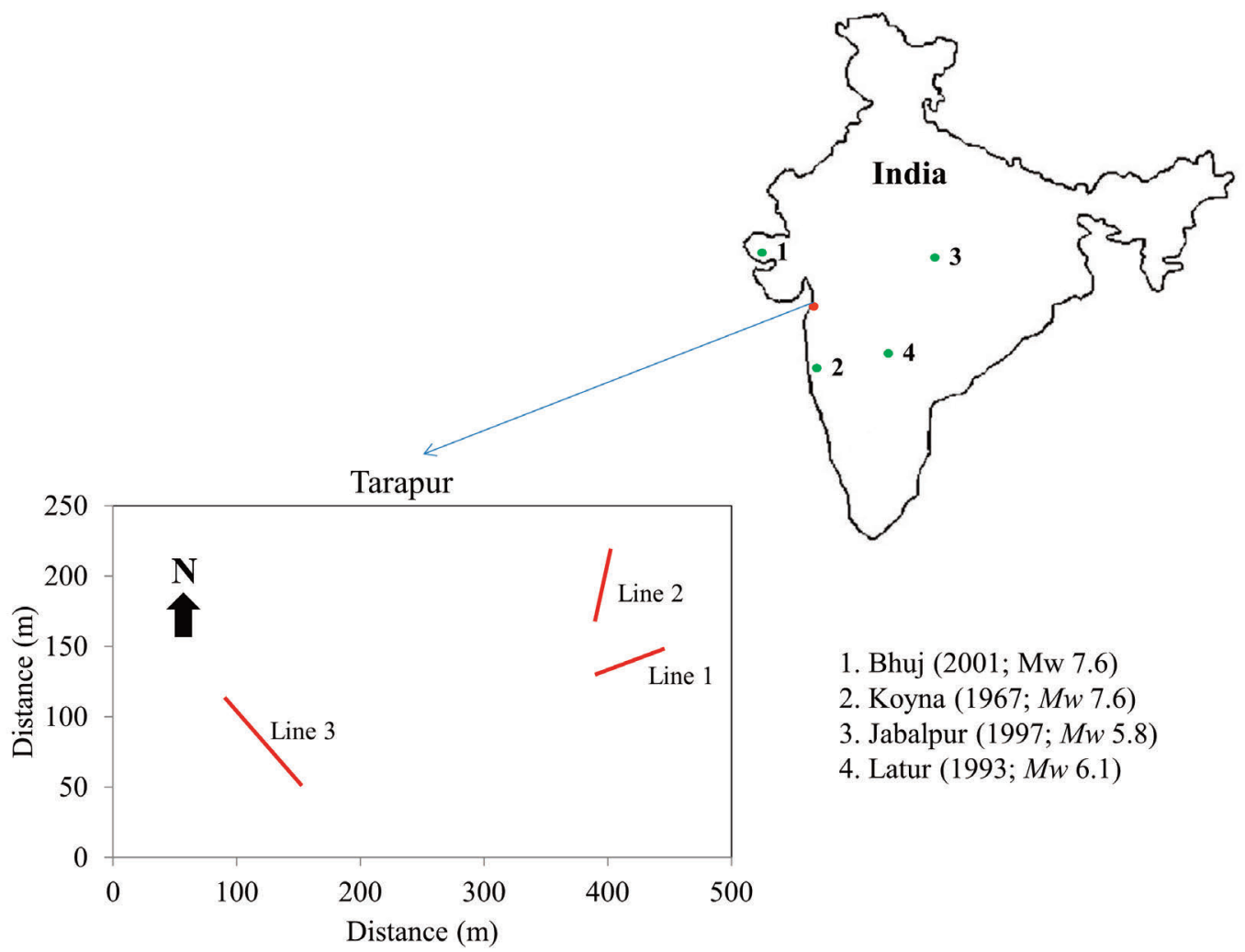

Figure 1. Study area along with the locations of the survey lines.

constant component of the signal in case there is one), application of an automatic gain control (AGC), band-pass filtering (to increase the signal to noise ratio) and the final GPR profile is generated. GPR data has been interpreted based on the available literature for GPR radar stratigraphy by Smith and Jol [1995], Gawthorpe et al. [1993], Jol and Bristow [2003], Moorman et al. [2003], Neal [2004] and Pellicer and Gibson [2011].

MASW is a seismic exploration technique that evaluates ground stiffness by measuring the shear wave velocity of the subsurface. In this study, MASW data were collected by 24 channel geode seismograph with a sampling interval of $1 \mathrm{~ms}$. Geophones of each $4.5 \mathrm{~Hz}$ frequency and 24 numbers spaced at $1 \mathrm{~m}$ intervals were used for the survey. A software package of Surfseis has been used to process the MASW data. During data analysis, each timedomain shot was converted to the frequency domain by using the fast Fourier transform approach (Park et al 1999). Then, from each transformed shot, a site-specific dispersion curve (a plot of phase velocity versus frequency) was generated. A 1D-Vs profile is generated from the dispersion curve by using an iterative nonlinear inversion process [Xia et al 1999]. The typical dispersion curve and inverted 1D velocity depth profile for the Tarapur site is shown in Figure 2. All the 1D shear wave velocity profiles along the survey line are interpolated by using a Kriging algorithm in a shot station sequential order and the final continuous 2D-Vs profile was generated. Based on the spatial variation shear wave velocity, different soil layers were identified. Previous studies in MASW by many researchers like Leucci et al. [2007], Maheswari et al. [2008], Anbazhagan and Sitharam [2009], Shaaban et al. [2013], and Mahajan et al. [2015] are used to interpret the 2D-Vs profiles.

These two geophysical test results were correlated with borehole data and the final subsurface profiles were generated in 2D. A similar kind of subsurface profiling at the Bangalore site using integrated geophysical approaches is mentioned in detail in Chandran and Anbazhagan [2017]. The final subsurface profiles were used for 2D nonlinear site response analysis using FLAC -2D program of version 7.0 [Itasca 2013] and amplification factors were generated. 1D site response analysis was also done at specific points in the survey lines using DEEPSOIL program of version 6.0 [Hashash et al., 2015] and the results were compared with the 2D site response results. Also, a parametric study has been done at the end of the study to quantitatively evaluate different ground motion parameters on 2D site response analysis. 


\section{Deepu Chandran et al.}

(a)

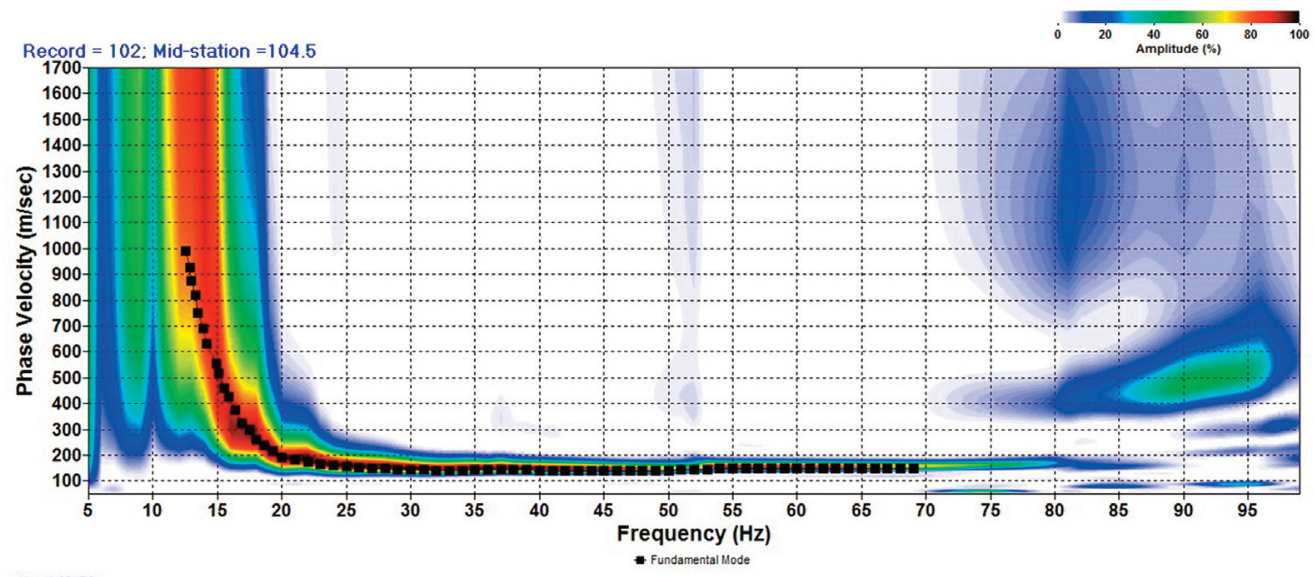

(b)

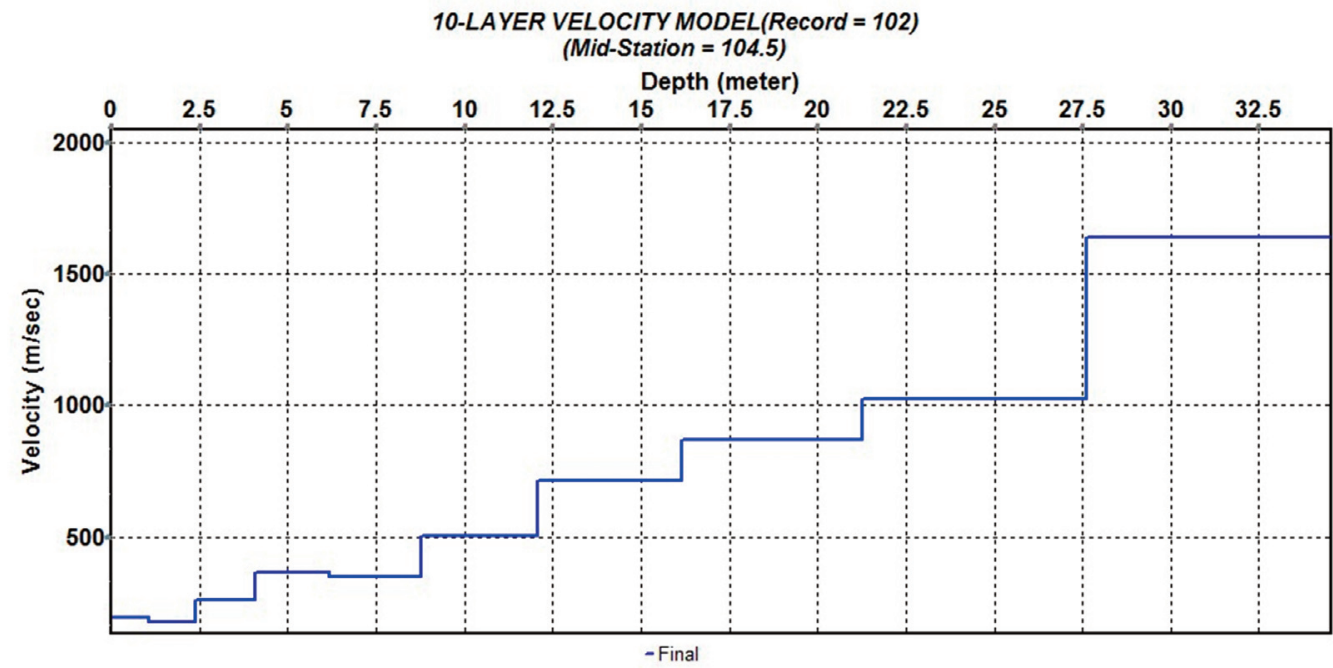

Figure 2. Typical MASW 1D velocity model at the Tarapur site. (a) Extracted dispersion curve. (b) Inverted 1D shear wave velocity profile.

\section{Subsurface profiling using integrated geophysical methods}

GPR and MASW surveys were conducted along the selected three survey lines. Boreholes were drilled up to 20 $\mathrm{m}$ and SPT tests were conducted as per IS 2131 (1981) at different depths in a borehole. The details of the borehole data are shown in Table 1. The borehole data show that clayey black cotton soil with very low SPT N value is present up to a depth of $3 \mathrm{~m}$ and after that weathered basalt rock starts and after that compacted basalt rock begins.

The typical GPR profile generated at line 1 is shown in Figure 3 (a). Here we can distinguish two distinctive layers based on the radar sequence and their interface is marked by a yellow dotted line. The depth of the top layer varies from 2.5 to $4 \mathrm{~m}$ and it is very clear due to the strong GPR reflection. This top layer mostly corresponds to the clayey black cotton soil and the bottom layer corresponds to the weathered basalt rock as in the borehole data (Table 1). The radar signal is getting attenuated after the top layer. This may be mainly because of the high clay content or salt content as all these survey lines are located very near to the sea. GPR profile shows too much of noise from a distance of 17 to $23 \mathrm{~m}$. This may be due to the presence of some boulders or electric poles nearby. GPR profiles for lines 2 and 3 are also interpreted similarly and are shown in Figures 4 (a) and 5 (a) respectively. GPR profiles at these two lines also have an almost similar trend as that at line 1 in which the GPR signal is very clear in the top layer approximately up to $3 \mathrm{~m}$ and after that, the signal is getting attenuating. In this case, GPR seems to be very effective to delineate the top layers compared to deeper layers. 
2D site response analysis of shallow bedrock sites

\begin{tabular}{|c|c|c|c|c|c|}
\hline \multirow{2}{*}{ BH no } & \multicolumn{2}{|c|}{ Depth (m) } & \multirow{2}{*}{$\begin{array}{l}\text { Thickness } \\
\text { (m) }\end{array}$} & \multirow{2}{*}{$\begin{array}{c}\text { Average } \mathbf{N} \\
\text { value }\end{array}$} & \multirow{2}{*}{ Description } \\
\hline & From & To & & & \\
\hline \multirow{3}{*}{ BH 1} & 0 & 3 & 3 & 12 & Clayey black cotton soil \\
\hline & 3 & 11 & 8 & $>50$ & Weathered basalt rock \\
\hline & 11 & 20 & 9 & $>50$ & Compacted basalt rock \\
\hline \multirow{3}{*}{ BH 2} & 0 & 3 & 3 & 13 & Clayey black cotton soil \\
\hline & 3 & 7 & 4 & $>50$ & Weathered basalt rock \\
\hline & 7 & 20 & 13 & $>50$ & Compacted basalt rock \\
\hline \multirow{3}{*}{ BH 3} & 0 & 3 & 3 & 13 & Clayey black cotton soil \\
\hline & 3 & 13 & 10 & $>50$ & Weathered basalt rock \\
\hline & 13 & 20 & 7 & $>50$ & Compacted basalt rock \\
\hline \multirow{3}{*}{$\mathrm{BH} 4$} & 0 & 3 & 3 & 16 & Clayey black cotton soil \\
\hline & 3 & 17 & 14 & $>50$ & Weathered basalt rock \\
\hline & 17 & 20 & 3 & $>50$ & Compacted basalt rock \\
\hline \multirow{3}{*}{ BH 5} & 0 & 3 & 3 & 11 & Clayey black cotton soil \\
\hline & 3 & 10 & 7 & $>50$ & Weathered basalt rock \\
\hline & 10 & 20 & 10 & $>50$ & Compacted basalt rock \\
\hline \multirow{3}{*}{ BH 6} & 0 & 3 & 3 & 13 & Clayey black cotton soil \\
\hline & 3 & 11 & 8 & $>50$ & Weathered basalt rock \\
\hline & 11 & 20 & 9 & $>50$ & Compacted basalt rock \\
\hline
\end{tabular}

Table 1. Typical soil profile at shallow sites from the SPT borehole data.

Typical 2D-Vs profile at line 1 is shown in Figure 3(b). It shows three sub-surface layers that are marked using black dotted lines. The layer 1 (7-15 m thick) has a shear wave velocity of $100-550 \mathrm{~m} \mathrm{~s}^{-1}$, whereas the layer 2 located at the depth range $25-30 \mathrm{~m}$ has a velocity of $550-1100 \mathrm{~m} \mathrm{~s}^{-1}$. Layer 3 is extended up to $35 \mathrm{~m}$ depth and is having a velocity range of $1100-1600 \mathrm{~m} / \mathrm{s}$. Top layer 1 most likely corresponds to the clayey black cotton soil at the top and weathered basalt rock at the bottom. But the interface between this soil layer and the weathered rock is not clearly visible in Figure 3(b). Layer 2 mostly corresponds to the compacted basalt rock and layer 3 mostly corresponds to hard basalt rock with very high velocity. MASW profiles (2D-Vs profiles) for lines 2 and 3 are also interpreted similarly and are shown in Fig. 4(b) and 5(b) respectively. MASW profiles at these two lines also have a three-layered structure similar to line 1 . The top layer of black cotton soil cannot distinguish clearly in line 2 and 3 similar to line 1. In this case, MASW seems to be very effective to delineate the deeper layers compared to GPR.

In the case of line 1, the GPR profile (Figure 3a) gives the information about the spatial variation of the top clayey layer and the MASW profile (Figure 3b) gives the information of the deeper layers. Hence by integrating the top layer information from GPR and the deeper layer information from MASW, the final 2D subsurface profile is generated (Figure 3c). Four distinctive layers are identified in the final 2D profile. The top clayey black cotton soil layer has an average Vs value of $120 \mathrm{~m} / \mathrm{s}$. The second layer is the weathered rock of basalt with an average Vs value of $360 \mathrm{~m} / \mathrm{s}$. Layer 3 and 4 are compacted basalt rock and hard rock of basalt with an average shear wave velocity of $900 \mathrm{~m} / \mathrm{s}$ and $1300 \mathrm{~m} / \mathrm{s}$ respectively. Similar to line 1 the final 2D subsurface profiles of lines 2 and 3 are also generated and they are shown in figure 4(c) and 5(c) respectively. The final 2D subsurface profile of line 3 (Figure 5c) shows almost uniform layers while compared to line 1 and line 2. All these actual subsurface profiles are further used for the 2D site response analysis which will be mentioned in detail in the upcoming sections. 


\section{Deepu Chandran et al.}
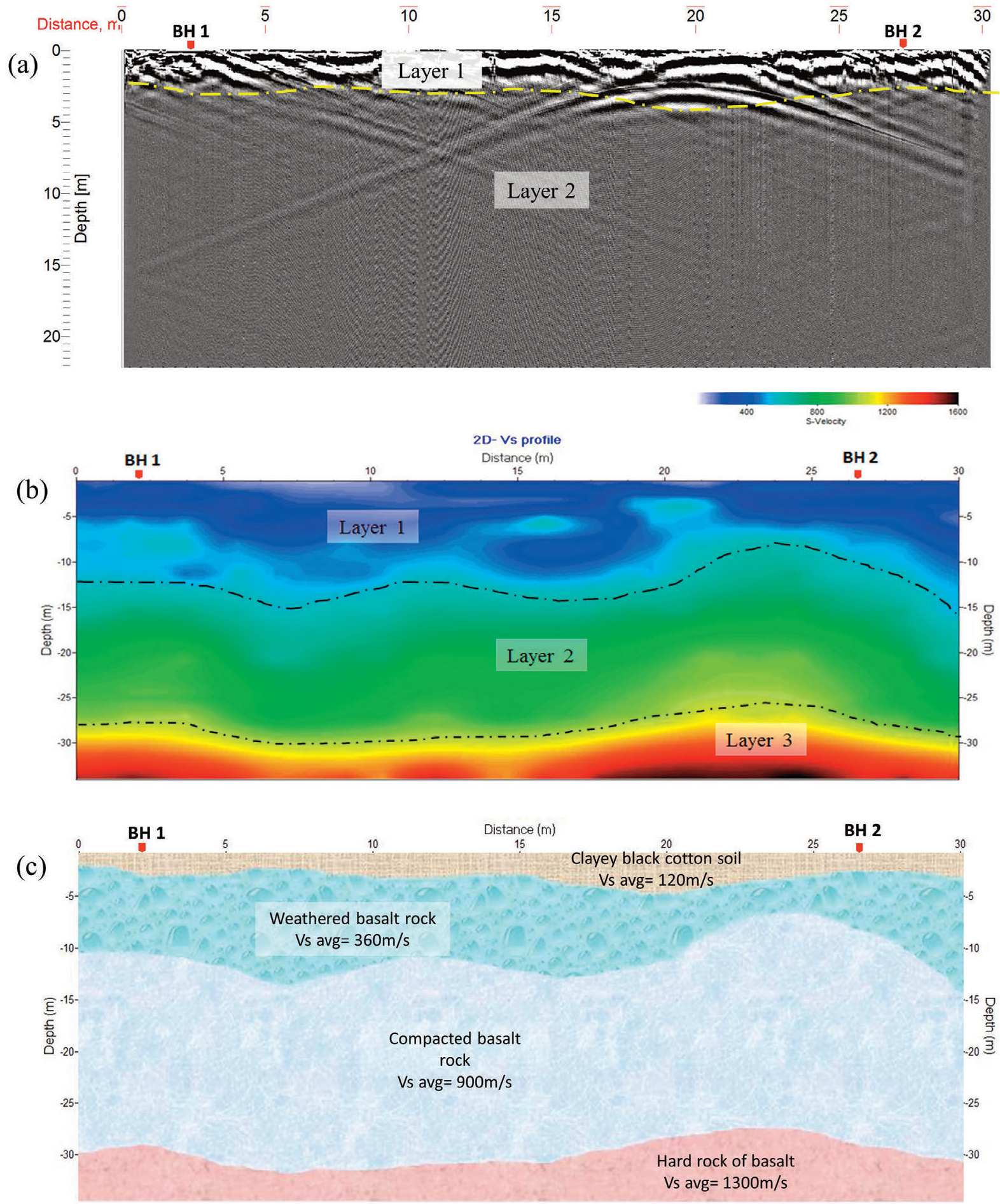

Figure 3. Subsurface profiling at line 1. (a) GPR profile. (b) MASW - 2D profile. (c) Final subsurface profile by integrating all the methods. 

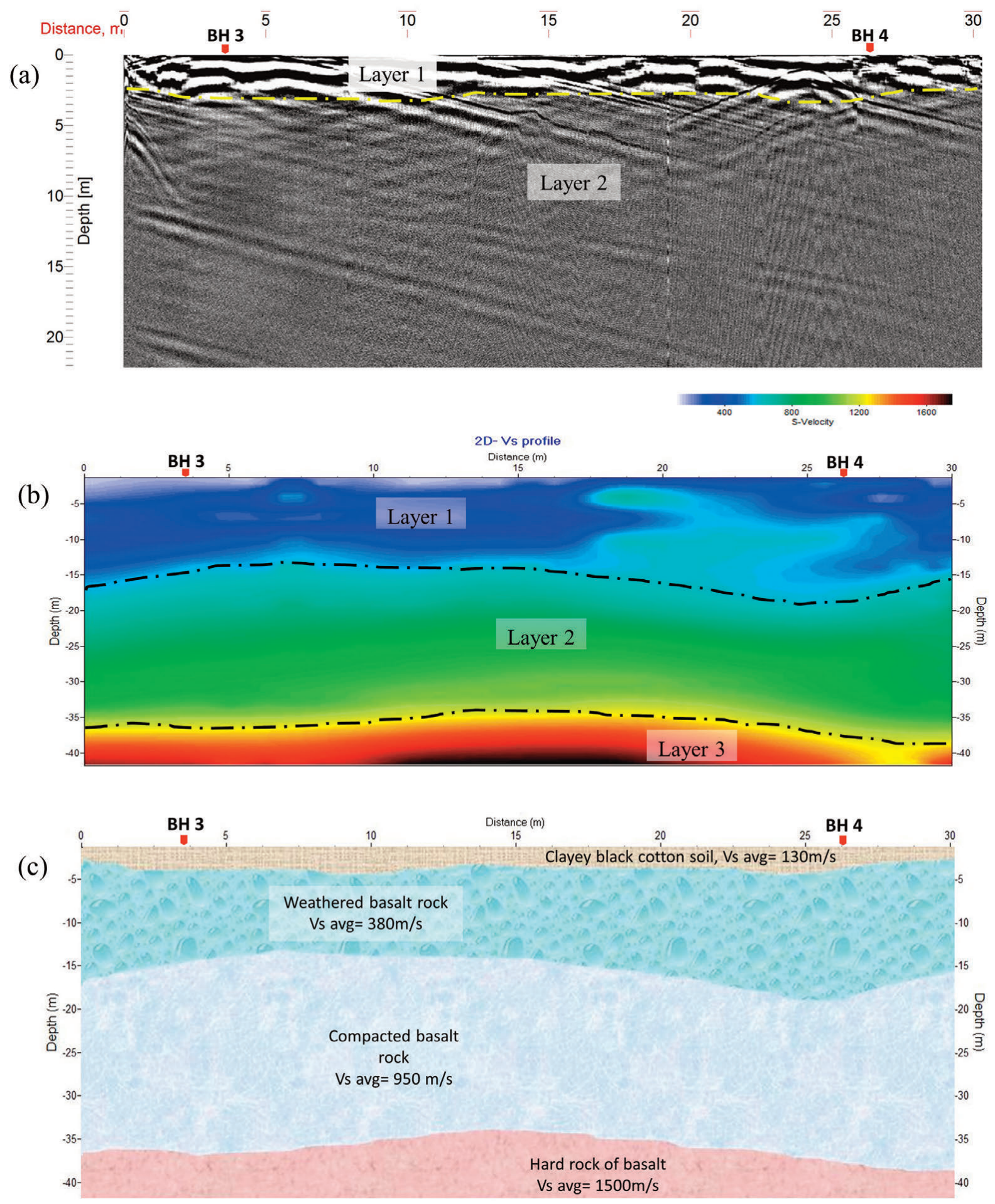

Figure 4. Subsurface profiling at line 2. (a) GPR profile. (b) MASW - 2D profile. (c) Final subsurface profile by integrating all the methods. 
Deepu Chandran et al.
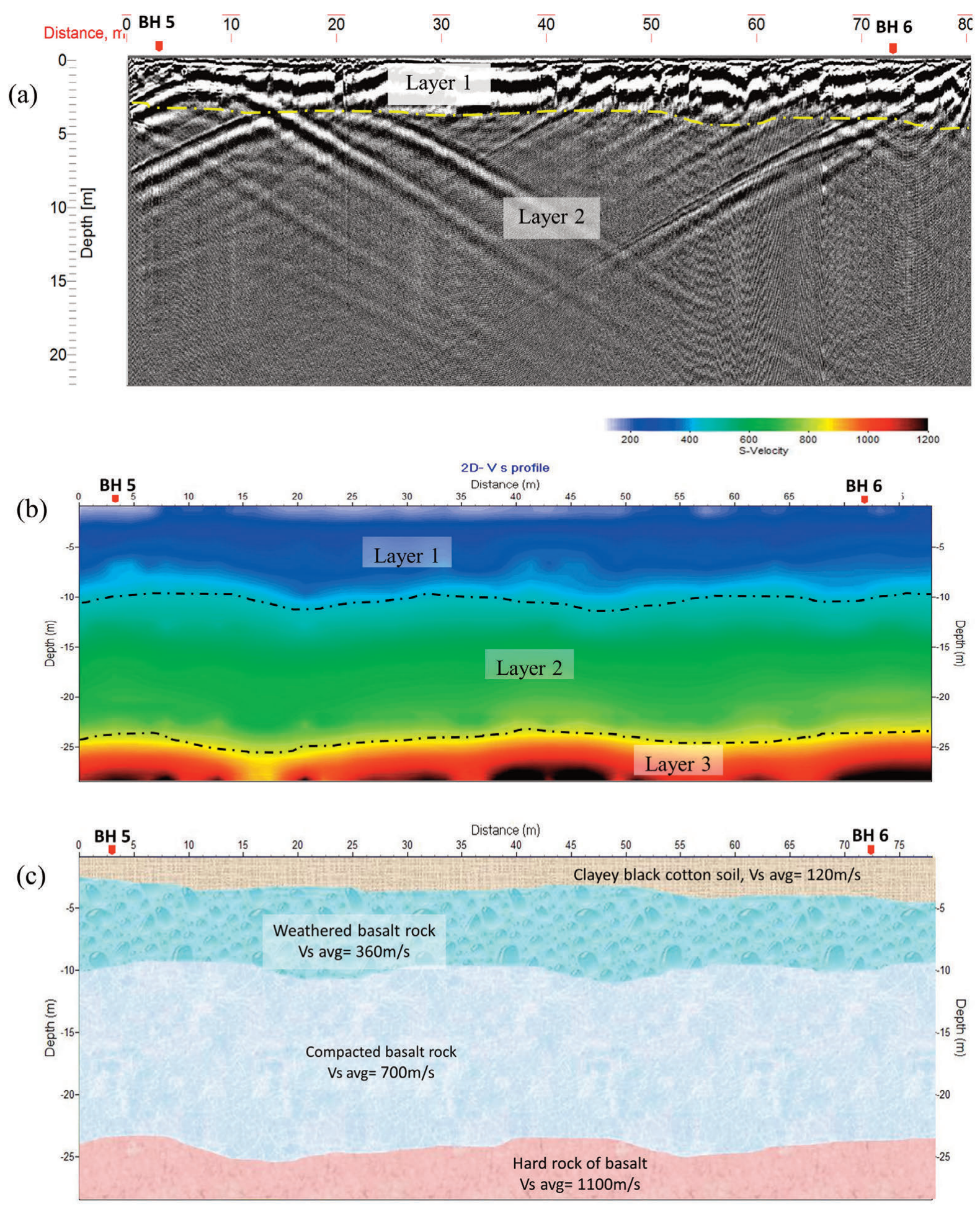

Figure 5. Subsurface profiling at line 3. (a) GPR profile. (b) MASW - 2D profile. (c) Final subsurface profile by integrating all the methods. 


\section{2D dynamic modeling}

Two-dimensional dynamic analysis has been carried out by modeling three integrated profiles in FLAC - 2D [Itasca, 2013]. FLAC is an explicit finite difference method that uses Lagrangian analysis to model the soil profile [Itasca, 2013]. The materials are assumed to be elastic and dry. Quiet boundaries were used at the base of the model to simulate the real situation of interaction between the bedrock and the soil [Lysmer and Kuhlemeyer, 1969]. To simulate the infiniteness of the media at sides free-field boundaries were set at the vertical boundaries [Cundall et al., 1980]. The spatial element was selected smaller than one-tenth of the wavelength associated with the highest frequency component of the wave [Kuhlemeyer and Lysmer, 1973]. Hysteretic damping is used for the energy dissipating response. The backbone curves selected are Sun et al. [1988] upper limit (UL) curve for the clay and Schnabel [1973] curve is used for the rock.

\section{Selection of input motion}

The selection of appropriate input ground motion is one of the main aspects of the site response analysis. Shallow profiles under the consideration of this study are coming in the Peninsular India (PI) which is considered as a "Stable Continental Region (SCR)". There are many damaging earthquakes in this region of Peninsular India (PI), e.g. Bhuj (2001, Mw 7.6), Koyna (1967, M 6.5), Latur (1993, Mw 6.1) and Jabalpur (1997, Mw 5.8). These are intraplate earthquakes and also caused considerable damages close to the epicenter and at far-away distances. However, recordings of these earthquake events are not available due to poor instrumentation. Besides, by considering the previous hazard studies done by various researchers in Peninsular India, it can be found that study area may have potential for a PGA (Peak ground acceleration) value of $0.05 \mathrm{~g}$ to 0.2 g [Vipin et al., 2009; Kumar et al., 2012; Anbazhagan et al., 2009; Ramanna and Dodagaodar, 2012; Raghukanth, 2011]. Hence by considering all these factors thirteen intraplate recordings from all around the world have been selected for the study from Anbazhagan et al. [2017]. Summary of selected ground motions is presented in Table 2 .

\begin{tabular}{lcccccc} 
Earthquake & Station & $\begin{array}{c}\text { Motion } \\
\text { code }\end{array}$ & $\begin{array}{c}\text { PGA } \\
\mathbf{( g )}\end{array}$ & $\begin{array}{c}\text { Epidist } \\
\mathbf{( k m )}\end{array}$ & $\begin{array}{c}\text { Predominant } \\
\text { period, } \\
\text { Tp (Sec) }\end{array}$ & Magnitude \\
Saguaney 1988 & St. Ferreol & A1-enr & 0.121 & 115.827 & 0.15 & 5.6 \\
\hline Saguaney 1989 & Quebec & A2-enr & 0.0506 & 147.615 & 0.1 & 5.6 \\
\hline Saguaney 1990 & Baie-St-Paul & A7-ent & 0.174 & 105.068 & 0.2 & 5.6 \\
\hline Saguaney 1991 & La & A8-enr & 0.124 & 124.192 & 0.15 & 5.6 \\
\hline Saguaney 1992 & St. Pascal & A9-en2 & 0.0558 & 164.996 & 0.15 & 5.6 \\
\hline Saguaney 1993 & Riviere-Ouelle & A10-ent & 0.057 & 148.398 & 0.15 & 5.6 \\
\hline Saguaney 1994 & Chicoutimi & A16-ent & 0.131 & 45.142 & 0.04 & 5.6 \\
\hline Saguaney 1995 & Andre-Lac-Jean & A17-enr & 0.156 & 91.847 & 0.04 & 5.6 \\
\hline Saguaney 1996 & Les & A20-enr & 0.126 & 112.94 & 0.2 & 5.6 \\
\hline Quebec 2005 & A61-2005 & A61-2005 & 0.07 & 29.696 & 0.04 & 5.4 \\
\hline Quebec 2006 & A21-2005 & A21-2005 & 0.084 & 13.3 & 0.05 & 5.4 \\
\hline Alaska 2008 & A21-2008 & A21-2008 & 0.077 & 5.553 & 0.03 & 4.7 \\
\hline Virginia 2011 & VA & Virginia & 0.098 & 53.5 & 0.05 & 5.8 \\
\hline
\end{tabular}

Table 2. Intraplate earthquake motion selected for the site response analysis from Anbazhagan et al. [2017]. 


\section{Deepu Chandran et al.}

\section{Site response analysis and amplification factor}

Two-dimensional nonlinear site response analyses are performed by using FLAC - 2D on all three locations subjected to thirteen input motions. Subsurface layer properties and backbone curves selected for the three locations are given in Table 3. The unit weight of the material corresponding to each layer is measured from the density Vs correlation [Anbazhagan et al., 2016]. Responses are recorded at the surface point of the soil profile and acceleration response spectra are generated. Response spectra were generated with a $5 \%$ damping. The amplification factor can be calculated in many ways. Average spectral amplification factor for different ranges of a period can be calculated from the spectral amplification plots and it is an effective way of expressing the spectral amplification [Dobry et al., 2000; Hall et al., 1975]. In this study, a short period amplification factor (Fc) range from $0.01 \mathrm{~s}$ to $0.06 \mathrm{~s}$ and long period amplification factor (Fs) range from $0.05 \mathrm{~s}$ to $1 \mathrm{~s}$ are taken similar to Aditya [2014] for the intraplate earthquake data. Factors Fc and Fs can be calculated using equations as follows:

$$
\begin{aligned}
& F c=\frac{R \text { soil }}{\operatorname{Rrock}} \frac{1}{0.05} \int_{0.01}^{0.06} \frac{R \operatorname{Ssoil}(T)}{\operatorname{Rrock}(T)} d T \\
& F s=\frac{R \operatorname{soil}}{\operatorname{Rrock}} \frac{1}{0.95} \int_{0.05}^{1} \frac{R \operatorname{Ssoil}(T)}{\operatorname{Rrock}(T)} d T
\end{aligned}
$$

where, RSsoil and RSrock are response spectra on soil and rock at a given period $T$, and Rsoil and Rrock are the hypocentral distances of soil and rock stations. The ratio of Rsoil/Rrock was assumed to be 1.0 in this study as rock and surface spectral hypocentral distance is similar. 1D site response analysis is done at specific points in the survey lines using DEEPSOIL program.

\begin{tabular}{cccccc} 
Line no & $\begin{array}{c}\text { Sub-surface } \\
\text { layer }\end{array}$ & Vs $\mathbf{( m / \mathbf { s } )}$ & $\begin{array}{c}\text { Unit weight } \\
\mathbf{( k N / \mathbf { m } ^ { 3 } )}\end{array}$ & Soil type & $\begin{array}{c}\text { Modulus reduction curve and } \\
\text { damping curve selected }\end{array}$ \\
\cline { 2 - 6 } Line 1 & Layer 1 & 120 & 13.29 & Clay & Sun et al. [1988], UL \\
\cline { 2 - 6 } & Layer 2 & 360 & 16.56 & Rock & Schnabel [1973] \\
\cline { 2 - 6 } & Layer 3 & 900 & 19.88 & Rock & Schnabel [1973] \\
\hline \multirow{2}{*}{ Layer 4 } & 1300 & 21.40 & Rock & Schnabel [1973] \\
\hline & Layer 1 & 130 & 13.50 & Clay & Sun et al. [1988], UL \\
\cline { 2 - 6 } & Layer 2 & 380 & 16.74 & Clay & Schnabel [1973] \\
\cline { 2 - 6 } & Layer 3 & 950 & 20.10 & Clay & Schnabel [1973] \\
\hline \multirow{2}{*}{ Line 3 } & Layer 4 & 1500 & 22.02 & Rock & Schnabel [1973] \\
\cline { 2 - 6 } & Layer 2 & 120 & 13.29 & Clay & Sun et al. [1988], UL \\
\cline { 2 - 6 } & Layer 3 & 700 & 16.56 & Rock & Schnabel [1973] \\
\cline { 2 - 6 } & Layer 4 & 1100 & 20.70 & Rock & Schnabel [1973] \\
\hline
\end{tabular}

Table 3. Subsurface layer properties selected for the site response analysis at the shallow sites.

Typical acceleration response spectra corresponding to an input motion A1-enr for line 1 is shown in Figure 6. It shows that $2 \mathrm{D}$ spectral accelerations are different from 1D and it is comparatively higher than 1D. Variations of short and long period amplification factors (Fc and Fs respectively) with distance corresponding to ground motion 
A1-enr are shown in Figure 7. It shows that the spectral amplification pattern in terms of Fc and Fs are differing for 1D and 2D. This difference is higher in the case of Fc and it is slighter in the case of Fs. The amplification pattern in terms of Fc and Fs for all the 13 intraplate ground motions is shown in Figure 8. It shows that 2D amplifications are different from 1D. There is a remarkable variation in the $2 \mathrm{D}$ amplification pattern in terms of Fc values. The 2D amplifications are higher than 1D, especially for Fc. As can be seen, the 2D geometry of the sub-surface is more sensitive to the higher frequency content of ground motion. Amplification pattern corresponds to all the ground motions in terms of long period amplification factor (Fs) shows a uniform trend and is converging to a single line especially in the case of 1D (Figure 8).
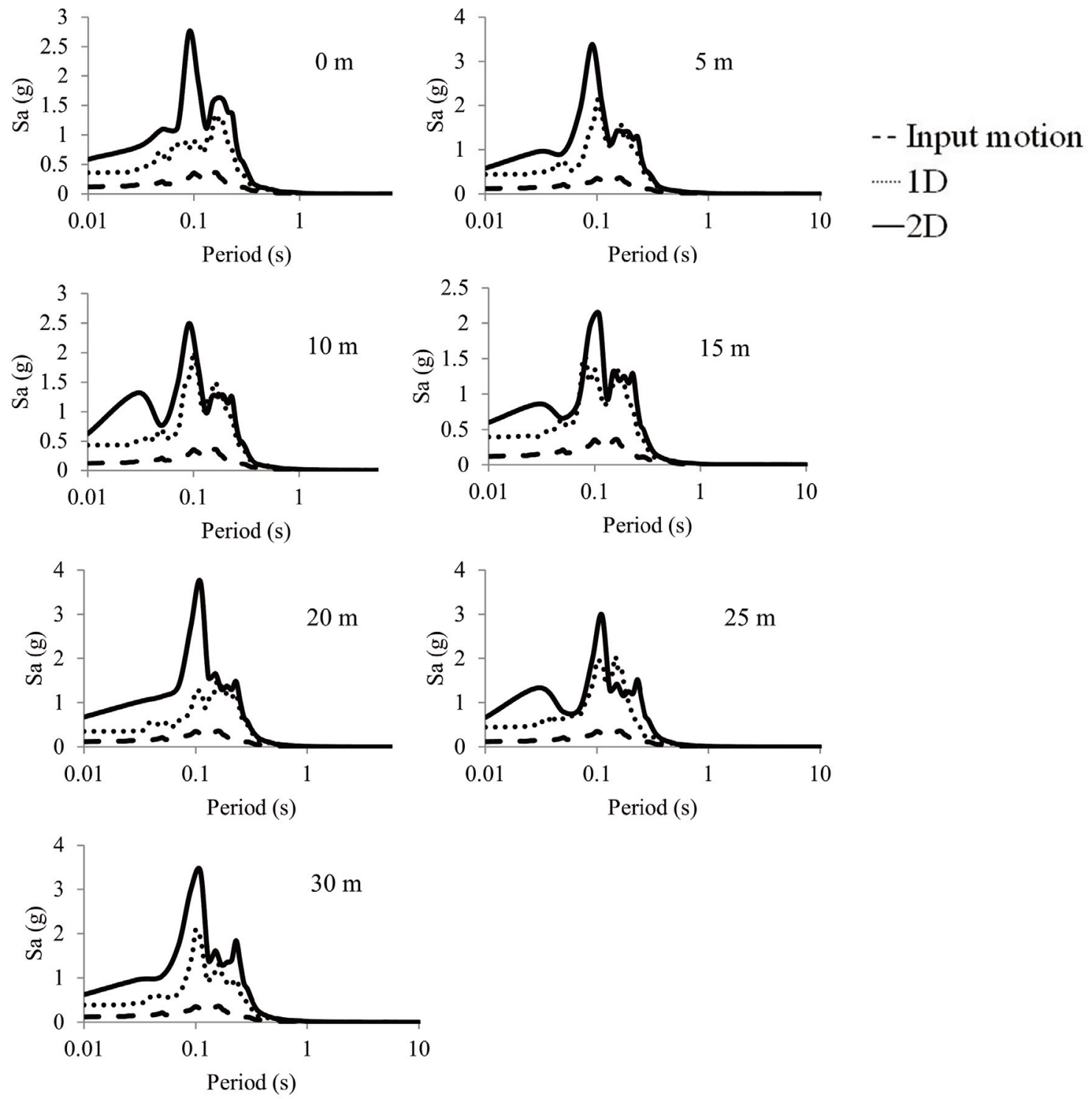

Figure 6. Comparison between 2D and 1D response spectra at different observation points along the survey line 1. 


\section{Deepu Chandran et al.}

Similar to line 1 typical spectral acceleration plots corresponding to the input motion A1-enr for the line 2 and 3 are shown in Figures 9 and 12 respectively. Fc and Fs values corresponding to the ground motion A1-enr for lines 2 and 3 are shown in Figures 10 and 13 respectively. Amplification pattern in terms of Fc and Fs for lines 2 and 3 corresponding to all the 13 intraplate ground motions are shown in Figures 11 and 14 respectively. The amplification pattern of line 2 shows an almost similar trend of line 1 in which the 2D amplification is higher than that of 1D (Figures 9, 10 and 11). In the case of line 3, the amplification pattern shows some what a different trend compared
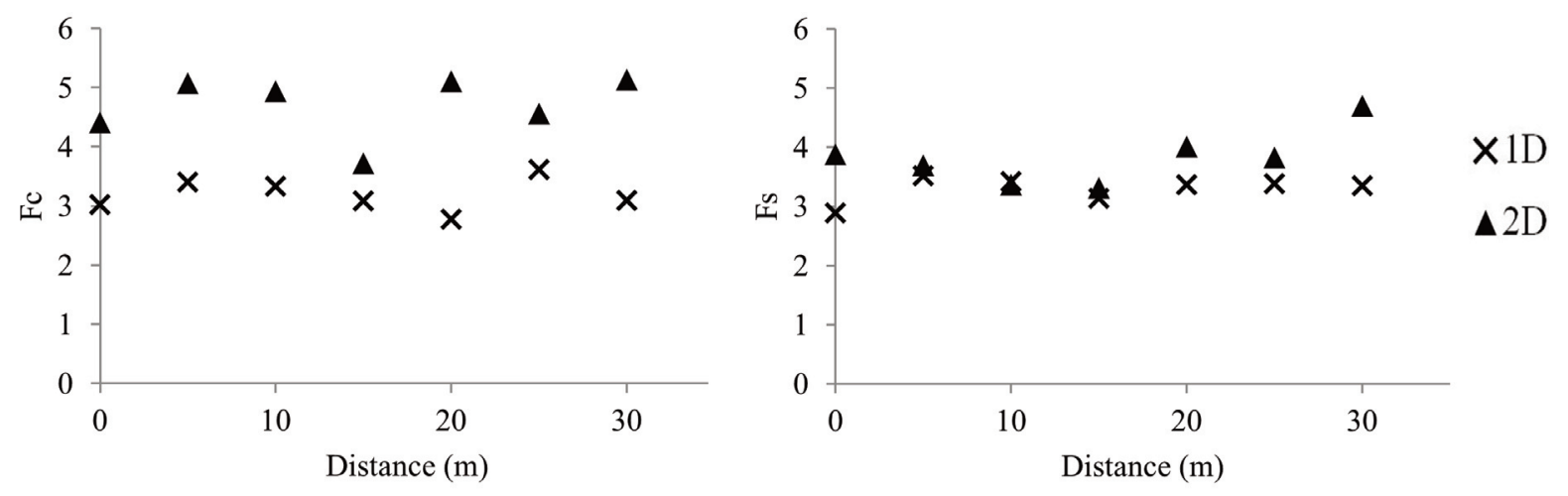

Figure 7. Variation of 2D and 1D amplification factors Fc and Fs along the survey line 1 corresponding to the ground

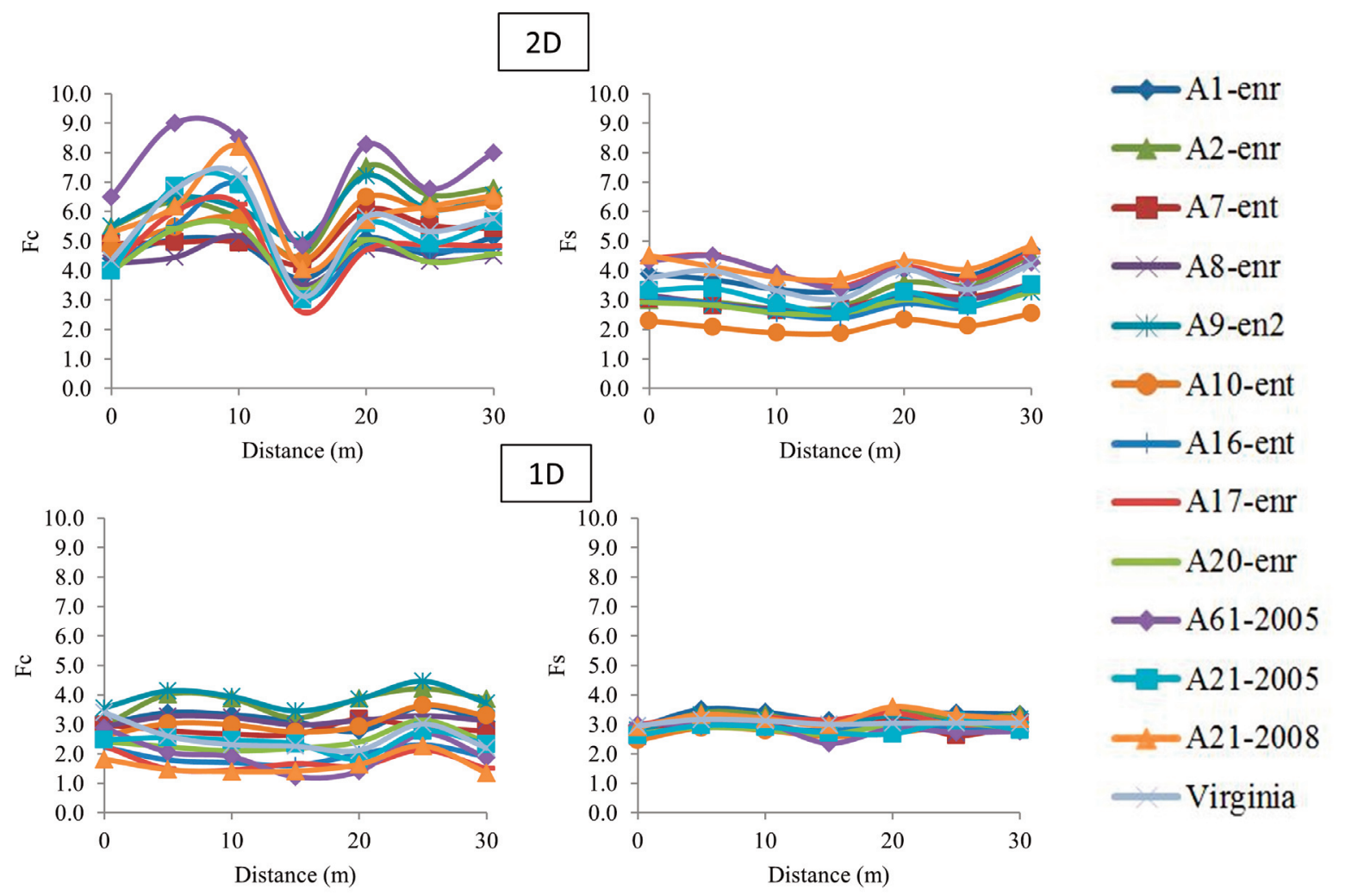

Figure 8. 2D and 1D amplification pattern in terms of Fc and Fs for all the 13 intraplate ground motions corresponding to line 1. 
to the other two lines 1 and 2. The intensity of spectral amplification is almost the same for both 1D and 2D corresponding to the ground motion A1-enr for line 3 (Figures 12 and 13). In a few cases, 1D amplification seems to be slightly higher than 2D. Amplification pattern in terms of Fc corresponding to all the 13 intraplate ground motions for line 3 (Figure 14) is not showing a remarkable variation as in the case of the other two lines 1 and 2. This is mainly because the subsurface layers are more uniform for line 3 when compared to the other two lines.

The responses (Fc and Fs) of all the thirteen ground motions expressed in terms of their Mean value and maximum standard deviation (Max SD) value and are shown in Figures 15 and 16 respectively. Now it is more clear and easy to compare the effect of 2D and $1 \mathrm{D}$ amplification pattern corresponding to each survey line. The results confirm the 2D amplifications are higher and more complex than 1D especially in the case of Fc. The pattern of 1D amplification almost shows a uniform trend for all the lines. Also as mentioned earlier, the 2D amplification in the case of line 3 is not showing a huge variation as in the case of the other two lines due to the higher uniformity in that profile (Line 3). This shows that actual 2D amplification is highly sensitive to the underground heterogeneity which cannot be captured through the conventional 1D model.
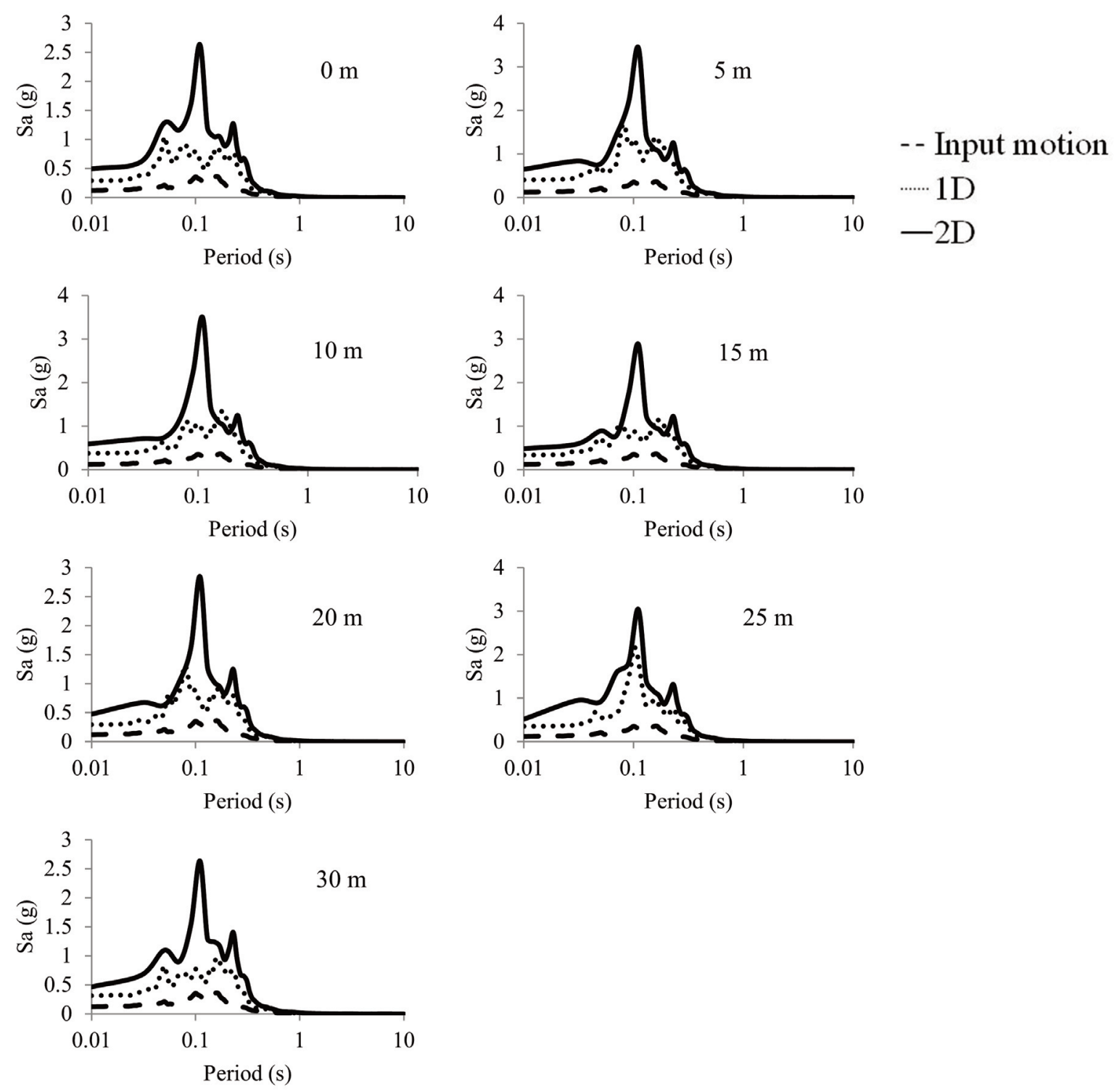

Figure 9. Comparison between 2D and 1D response spectra at different observation points along the survey line 2. 

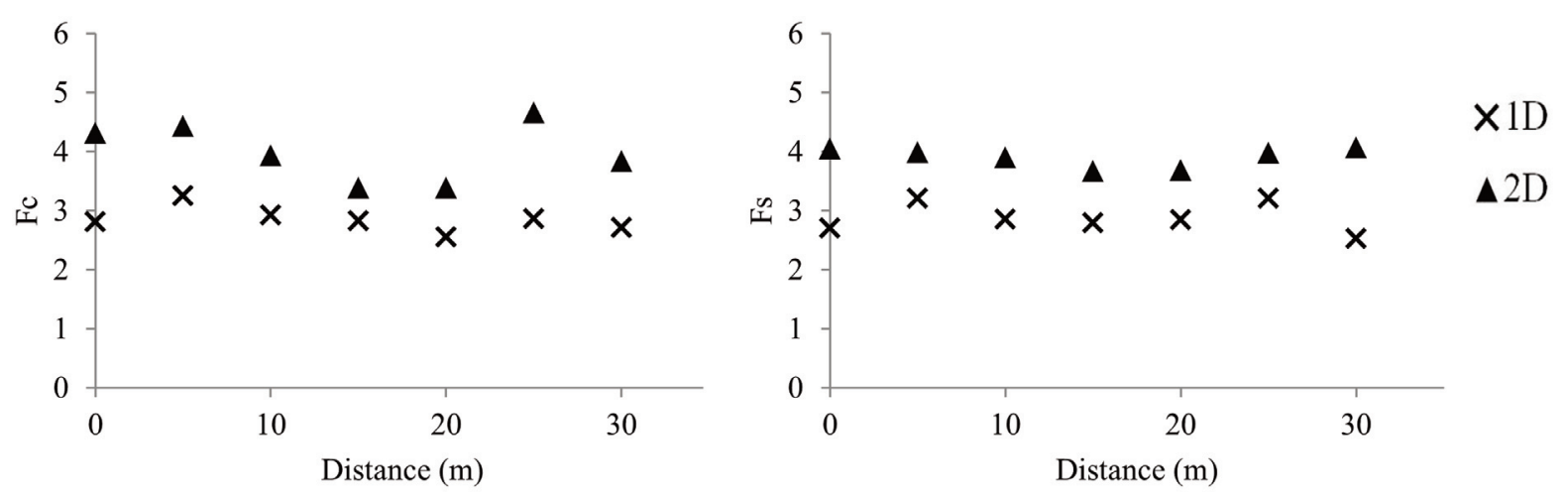

Figure 10. Variation of 2D and 1D amplification factors Fc and Fs along the survey line 2 corresponding to the ground
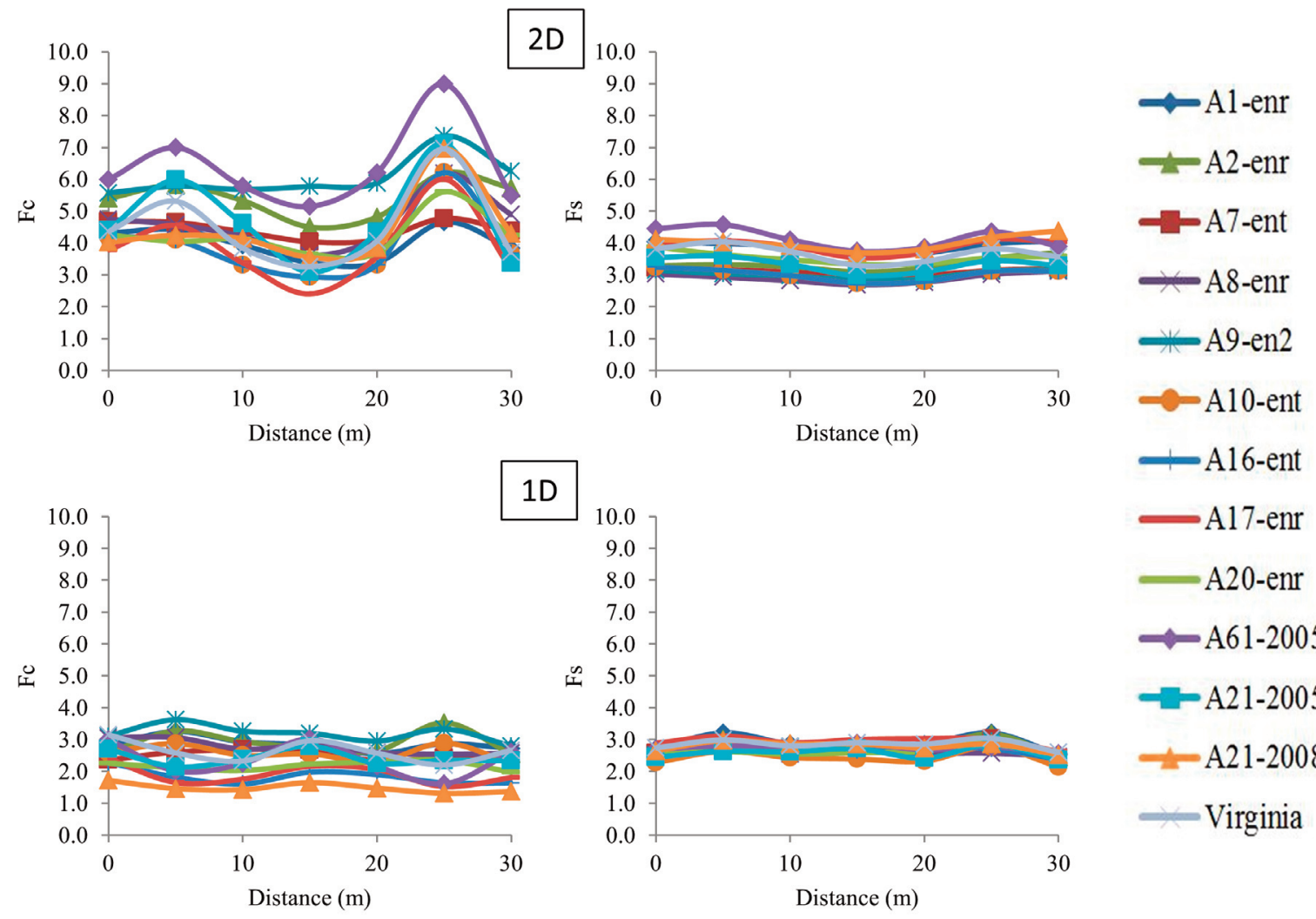

A17-enr

A20-enr

$-\mathrm{A} 61-2005$

A21-2005

$-\mathrm{A} 21-2008$

$\longrightarrow$ Virginia

Figure 11. 2D and 1D amplification pattern in terms of Fc and Fs for all the 13 intraplate ground motions corresponding to line 2 . 

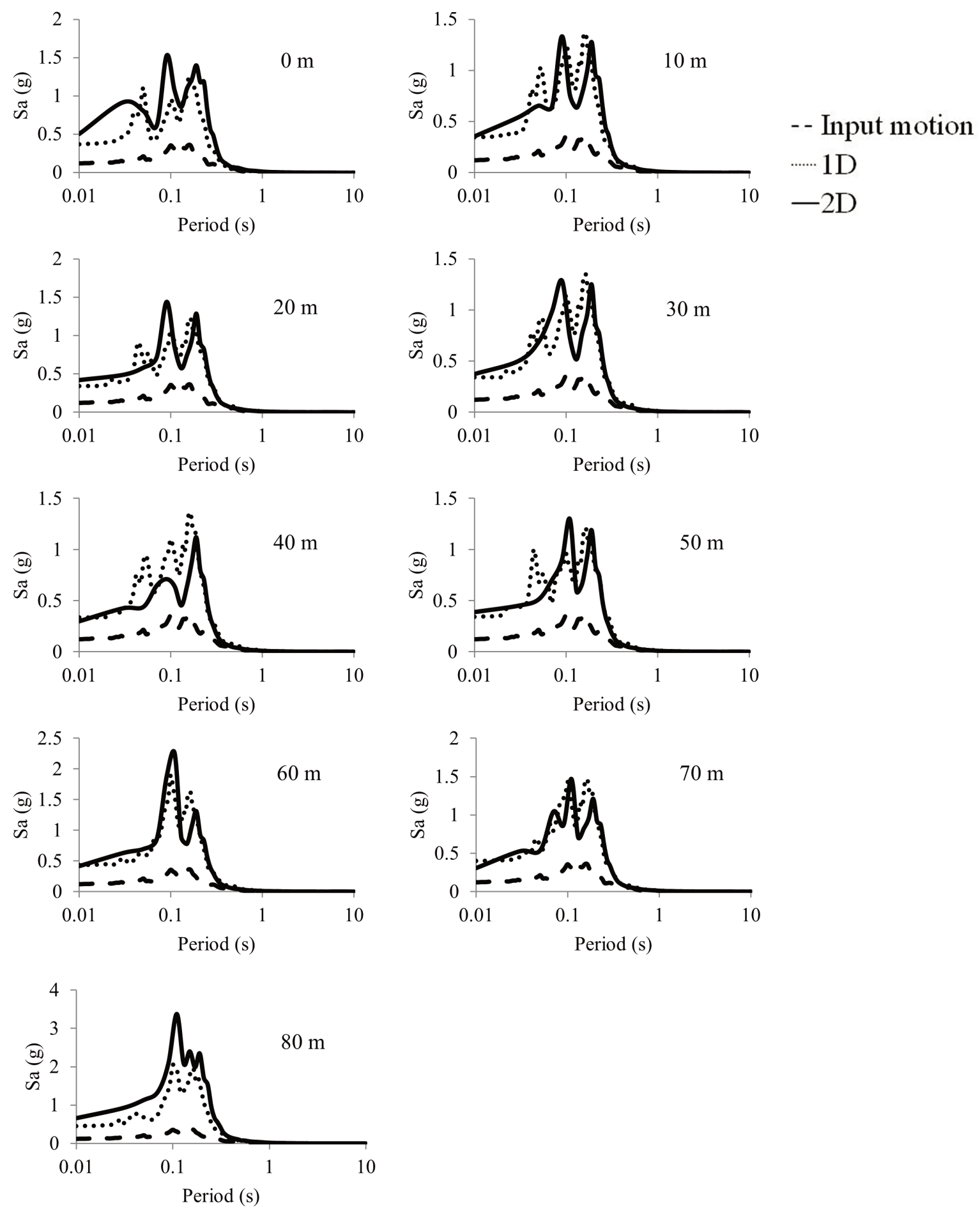

Figure 12. Comparison between 2D and 1D response spectra at different observation points along the survey line 3. 

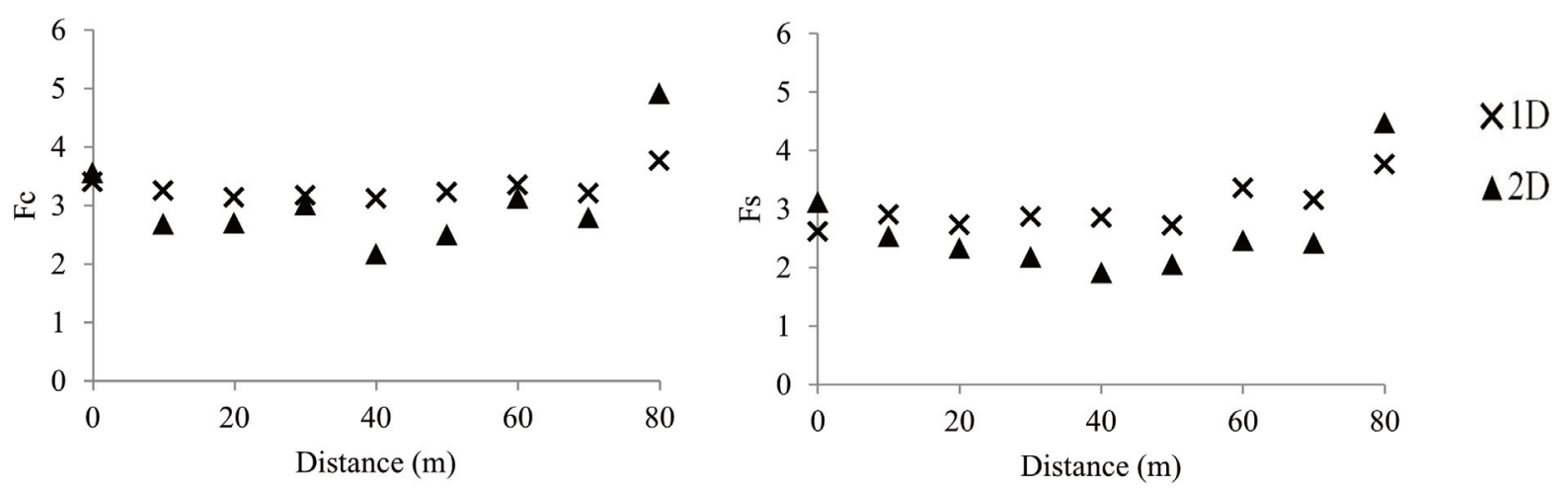

Figure 13. Variation of 2D and 1D amplification factors Fc and Fs along the survey line 3 corresponds to the ground motion A1-enr.

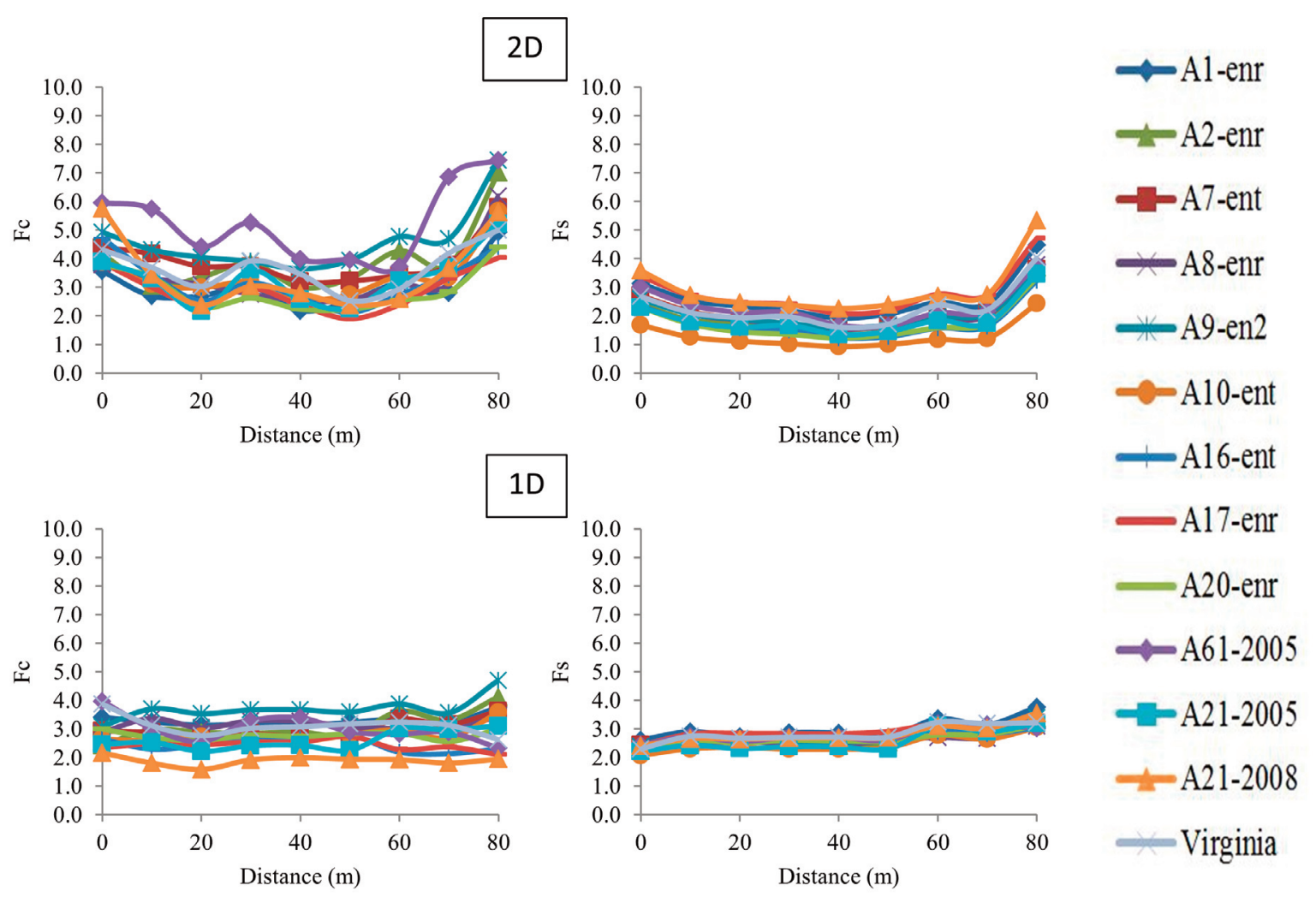

Figure 14. 2D and 1D amplification pattern in terms of Fc and Fs for all the 13 intraplate ground motions corresponding to line 3. 
2D site response analysis of shallow bedrock sites

(a)

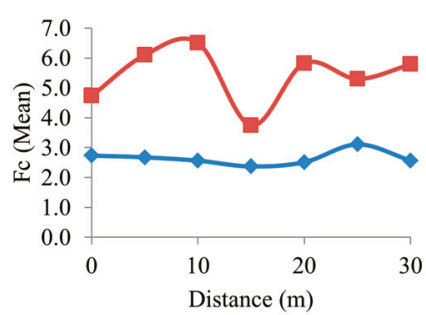

(b)

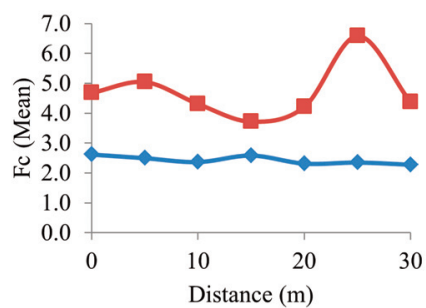

(c)

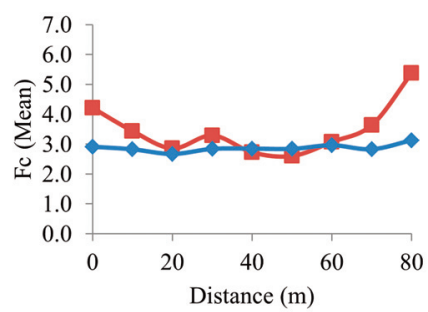

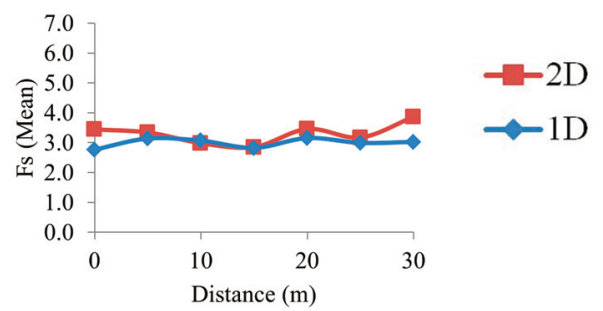
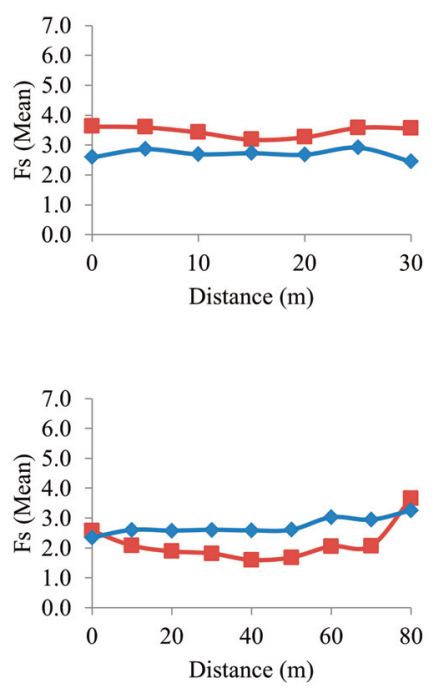

Figure 15. Comparison of 2D and 1D amplification factors ( $\mathrm{Fc}$ and Fs)in terms of their mean value. (a) Line 1. (b) Line 2. (c) Line 3.

(a)

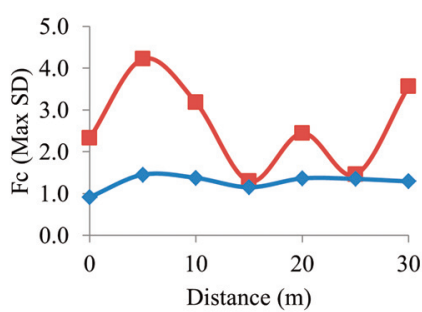

(b)

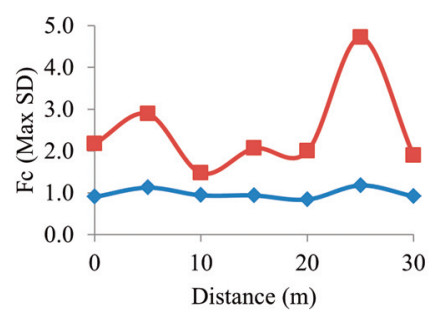

(c)

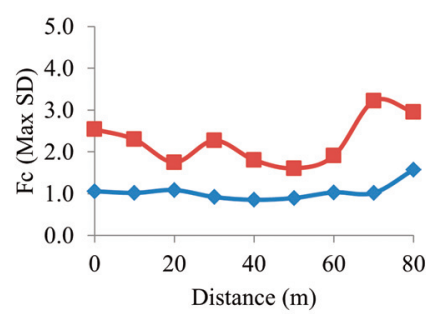

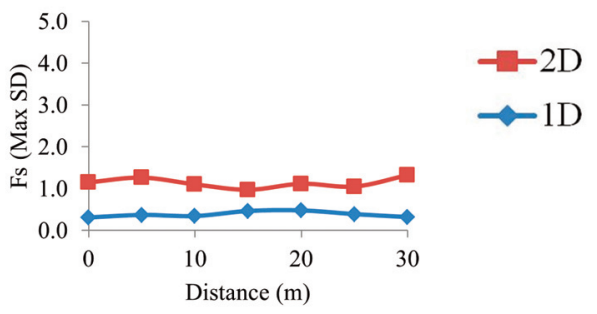
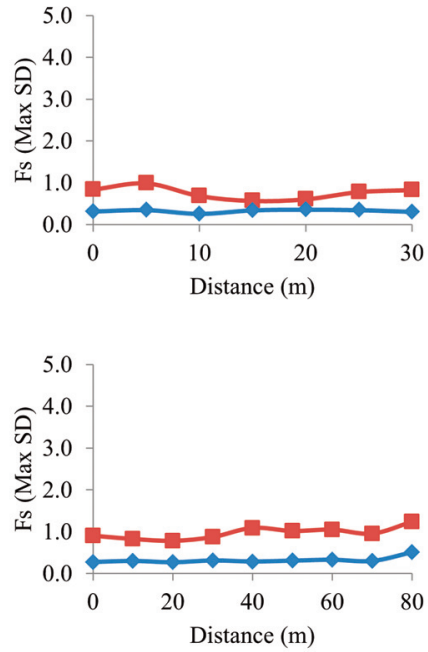

Figure 16. Comparison of 2D and 1D amplification factors ( $F c$ and Fs)in terms of their Max SD value. (a) Line 1. (b) Line 2. (c) Line 3 . 


\section{Deepu Chandran et al.}

\section{Parametric study}

A parametric study has been done to quantitatively evaluate the effect of different ground motion characteristics on the 2D site response. A synthetic 2D profile of $50 \mathrm{~m}$ length and $30 \mathrm{~m}$ depth has been generated as shown in Figure 17. This synthetic profile consists of four subsurface layers with different shear wave velocities. The material properties of each layer are given in Table 4. 2D and 1D site response analysis have been done on this synthetic profile similar to the survey lines. The effects of ground motion characteristics such as amplitude and frequency in site response are mentioned below in detail.

\begin{tabular}{ccccc} 
Sub-surface layer & Vs $(\mathbf{m} / \mathbf{s})$ & Unit weight $\left(\mathbf{k N} / \mathbf{m}^{3}\right)$ & Soil type & $\begin{array}{c}\text { Modulus reduction curve and } \\
\text { damping curve selected }\end{array}$ \\
\hline Layer 1 & 250 & 15.39 & Clay & Sun et al. [1988], UL \\
\hline Layer 2 & 350 & 16.46 & Rock & Schnabel [1973] \\
\hline Layer 3 & 750 & 19.17 & Rock & Schnabel [1973] \\
\hline Layer 4 & 1000 & 20.30 & Rock & Schnabel [1973] \\
\hline
\end{tabular}

Table 4. Subsurface layer properties selected for the site response analysis of the synthetic profile.

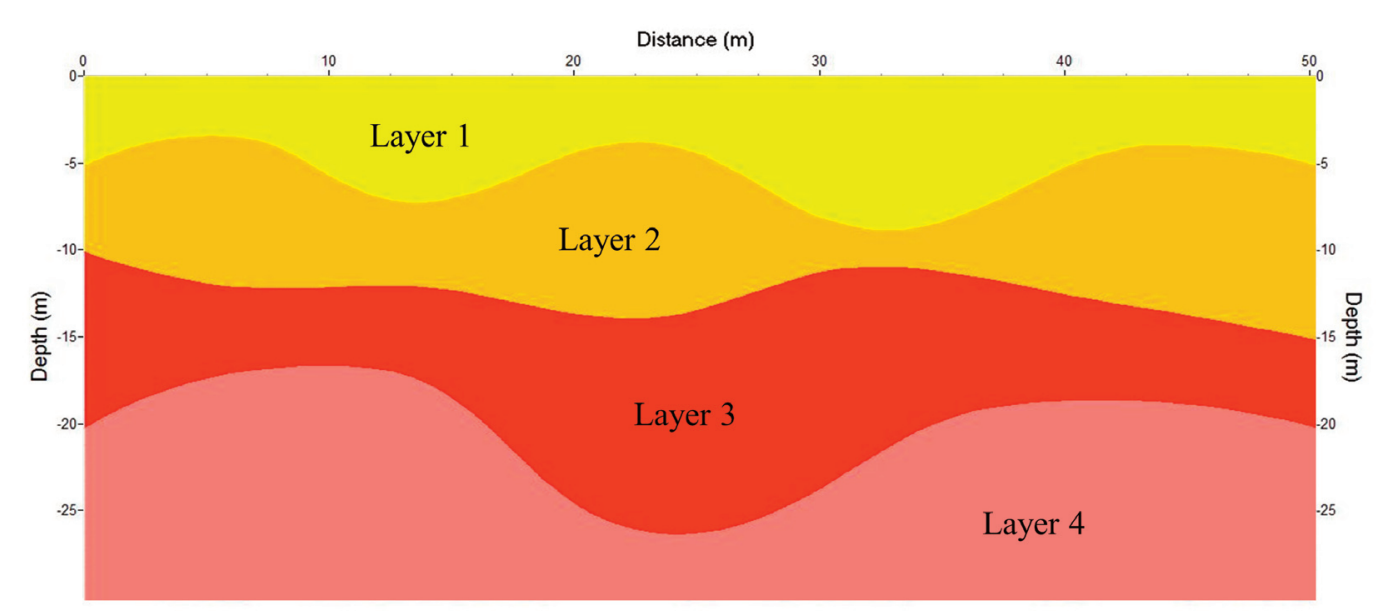

Figure 17. The synthetic 2D profile generated for the parametric study.

\subsection{Effect of the amplitude of ground motion}

An intraplate ground motion A2enr has been selected and it is scaled to three different amplitudes of $0.01 \mathrm{~g}, 0.1$ $\mathrm{g}$, and $1 \mathrm{~g}$ through linear scaling method. It is done by applying suitable scaling factors to the amplitude axis of the record [Jaramillo 2003, Watson-Lamprey 2007]. A2-enr is selected and it is scaled to three different PGA values 0.01 $\mathrm{g}, 0.1 \mathrm{~g}$, and $1 \mathrm{~g}$ by multiplying every data of acceleration record by a scale factor of $0.01 / \mathrm{PGA}_{\mathrm{A} 2 \text {-enr }}, 0.1 / \mathrm{PGA}_{\mathrm{A} 2 \text {-enr }}$ and $1 / \mathrm{PGA}_{\mathrm{A} 2 \text {-enr }}$ respectively. The result of site response analysis is shown in Figure 18. It shows that $2 \mathrm{D}$ amplifications are increasing with a decrease in the amplitude of ground motion especially in the case of Fc. The rate of increase in the amplification in 2D is very much higher than that of $1 \mathrm{D}$. 2D amplification pattern seems to be uniform when the intensity of ground motion increases to $1 \mathrm{~g}$ and it became very undulating when the amplitude decrease to $0.01 \mathrm{~g}$. This shows that the underground heterogeneity has very less effect on the site response if the ground motion intensity is very high and vice versa. 


\subsection{Effect of the frequency content of the ground motion}

Two intraplate ground motions A2-enr (predominant period, $\mathrm{Tp}=0.1 \mathrm{~s}$ ), A7-ent (predominant period= $0.2 \mathrm{~s}$ ) with high frequency content (see Table 2) and one interplate ground motion Diam [Loma Prieta, 1989 earthquake] (see Table 5) with relatively low frequency content (predominant period= $0.4 \mathrm{~s}$ ) were selected for the dynamic analysis. All three ground motions are scaled to the same PGA of $0.1 \mathrm{~g}$ through the linear scaling method. The response is shown in Figure 19. It shows that high-frequency motions A2-enr and A7-ent show higher amplification that the low-frequency motion Diam for both 1D and 2D. Compared to 1D amplification, the 2D amplification is very high for high-frequency motions, especially for Fc. The intensity of amplification is almost similar for 1D and 2D in the case of low-frequency ground motion Diam. 2D amplification pattern seems to be more complex corresponds to the high-frequency ground motions A2-enr and A7-ent, and the complexity is slighter in the case of low-frequency ground motion Diam. The results show that the 2D geometry is very sensitive to high-frequency ground motion.

\begin{tabular}{ccccccc} 
Earthquake & Station & $\begin{array}{c}\text { Motion } \\
\text { code }\end{array}$ & PGA (g) & Epidist (km) & Magnitude & $\begin{array}{c}\text { Predominant } \\
\text { period, Tp (s) }\end{array}$ \\
\hline $\begin{array}{c}\text { Loma Prieta, } \\
{[1989]}\end{array}$ & $\begin{array}{c}\text { CSMIP station } \\
58130\end{array}$ & Diam & 0.11 & 61.3 & 7 & 0.4 \\
\hline
\end{tabular}

Table 5. Low-frequency motion Diam selected for the parametric study.

The parametric study shows that underground heterogeneity is very sensitive to the ground motions with highfrequency content and low amplitude. All the thirteen intraplate ground motions used in this study are of high-frequency content (Predominant period, Tp $<0.2 \mathrm{sec}$ ) and low amplitudes (PGA $<0.2 \mathrm{~g}$ ) (see Table 2). This is one of the reasons why the $2 \mathrm{D}$ amplification is very much higher than that of the $1 \mathrm{D}$ amplification in many cases.

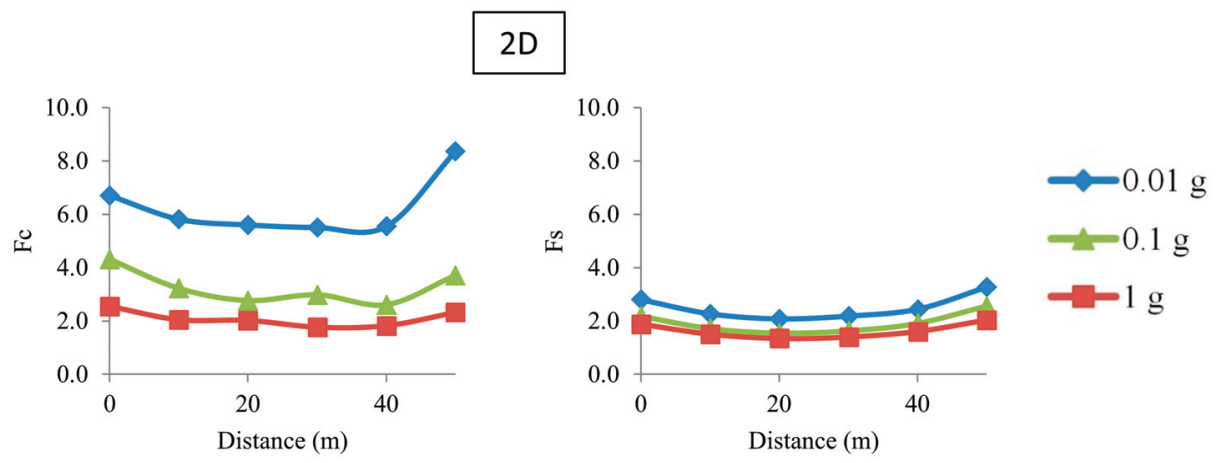

1D
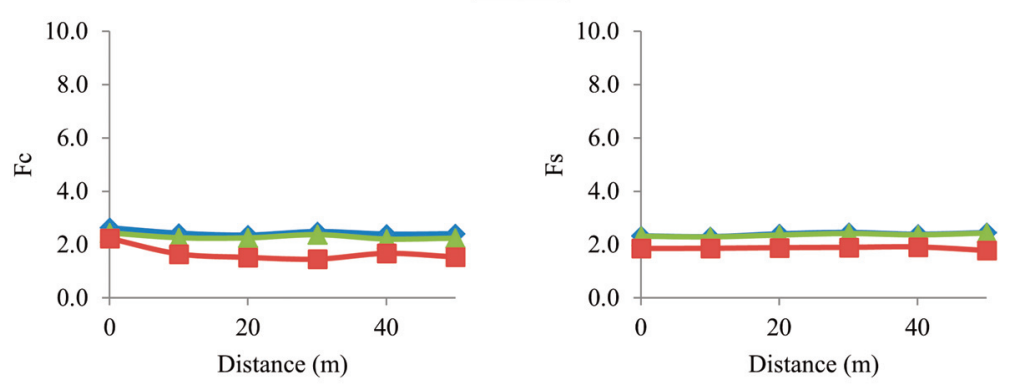

Figure 18. Variation of 2D and 1D amplification pattern corresponding to three ground motions with different amplitude values. 


\section{Deepu Chandran et al.}
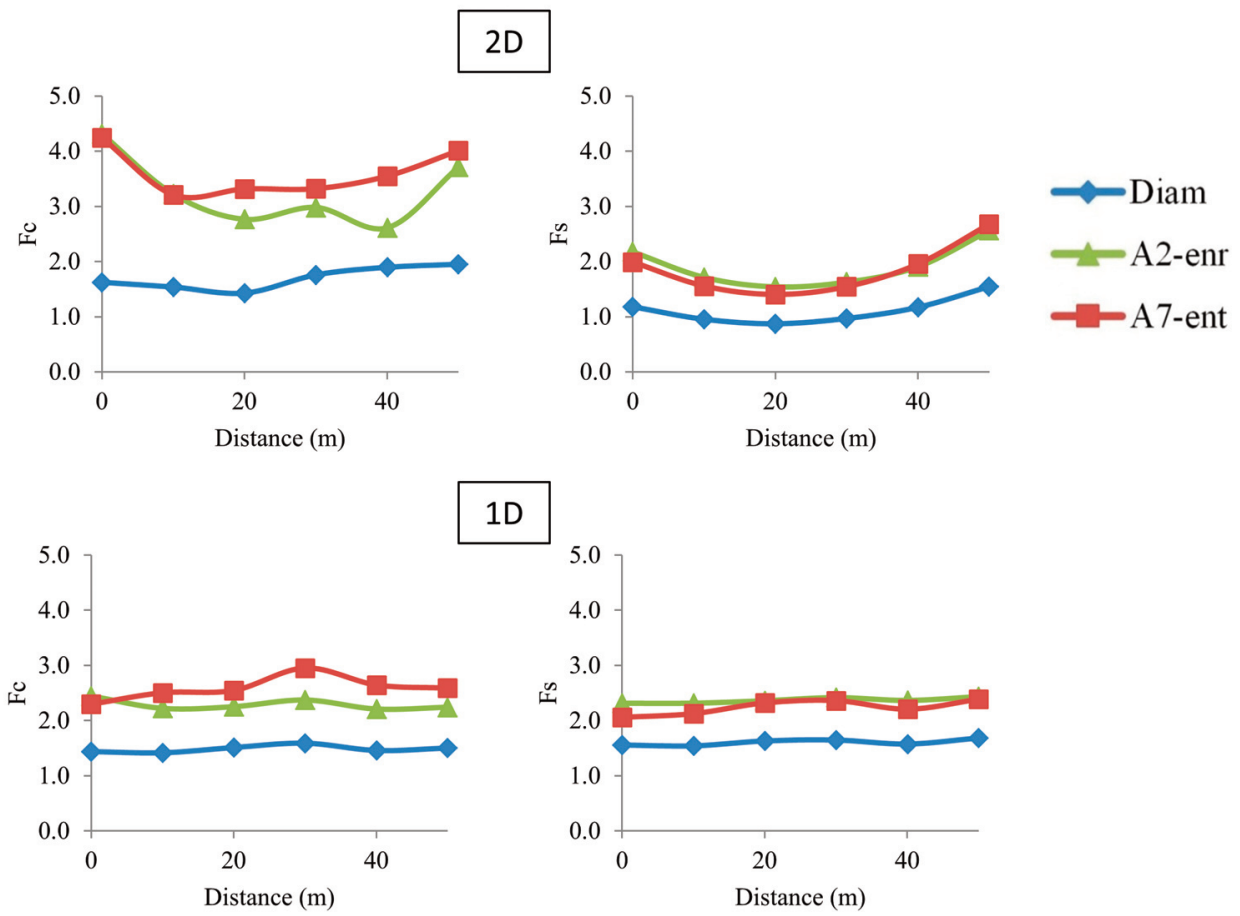

\section{D}

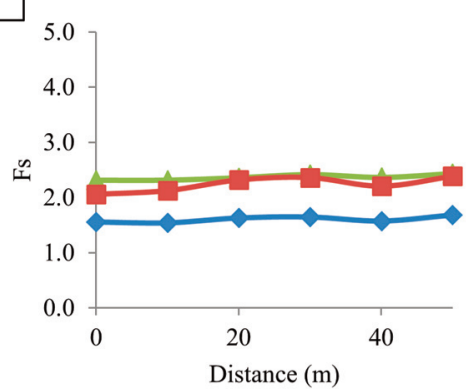

Figure 19. Variation of 2D and 1D amplification pattern corresponding to three ground motions with different frequency content.

\section{Summary and conclusions}

In this study subsurface profiling is done at three selected survey lines in Tarapur, India using integrated geophysical approaches by using GPR, MASW and drilled borehole data. GPR seems to be effective in delineating the subsurface layers at very shallow depth and MASW is effective for deeper depth. By integrating these two geophysical methods and correlating the results with the conventional SPT borehole data, the final subsurface profiles were generated.

Two-dimensional dynamic analysis was done on all the profiles using FLAC-2D through proper boundary conditions and includes hysteresis damping. Thirteen intraplate ground motions were selected for the analysis. The results of 2D dynamic analysis were compared with 1D analysis by DEEPSOIL. Results of site response analysis were expressed in terms of short-period amplification factor $(\mathrm{Fc})$ and long period amplification factor $(\mathrm{Fs})$ and the results show that $2 \mathrm{D}$ responses can rarely be captured through $1 \mathrm{D}$ analysis. The results show that the $2 \mathrm{D}$ geometry of sub-surface is more sensitive to the higher frequency content of ground motion especially for lines 1 and 2 in which the underground heterogeneities are very high. Hence the 2D amplification patterns corresponding to all the ground motions in terms of Fc values are more complex and giving higher values than the 1D. Amplification patterns in terms of Fc for line 3 are not showing a remarkable variation as in the case of the other two lines 1 and 2. This is mainly because the subsurface layers are more uniform for line 3 when compared to the other two lines. Amplification patterns in terms of Fs seem to be almost uniform and are converging to a single line especially in the case of 1D.

A parametric study has been carried out to quantitatively evaluate the effect of different ground motion characteristics on 2D site response analysis. A synthetic 2D profile has been generated and 2D dynamic analysis has been done on this profile by using ground motions with different amplitudes and frequency contents. The parametric study shows that the underground heterogeneity is very sensitive to the ground motions with high-frequency content and low amplitude. All the thirteen intraplate ground motions used in this study are of high-frequency content and low amplitudes. This is one of the reasons why the $2 \mathrm{D}$ amplification is very much higher than that of the $1 \mathrm{D}$ amplification in many cases. 
Acknowledgement. Authors would like to thank "Board of Research in Nuclear Sciences (BRNS)", Department of Atomic Energy (DAE), Government of India, for funding the project titled "Seismic site classification for Indian shallow soil deposits" (Ref. 888 No. Sanction No. 2012/36/33-BRNS-165 dated October 10, 2012).

\section{References}

Abhishek, K., P. Anbazhagan, T,G. Sitharam. (2013). Seismic site classification and empirical correlation between Standard Penetration Test N value and shear wave velocity for deep Soil Sites in Indo-Gangetic Basin, Pure Appl. Geophys. 170(3), 299-318.

Anbazhagan, P. and T.G. Sitharam (2008). Site characterization and site response studies using shear wave velocity, J. Seismol. Earthq. Engi. 10(2), 53-67.

Anbazhagan, P. and T.G. Sitharam (2009). Spatial Variability of the Depth of Weathered and Engineering Bedrock using Multichannel Analysis of Surface Wave Method, Pure Appl. Geophys. 166, 409-428.

Anbazhagan, P., T.G. Sitharam, K.S. Vipin (2009). Site classification and estimation of surface level seismic hazard using geophysical data and probabilistic approach, J. Appl. Geophys. 68(2), 219-30.

Anbazhagan, P., J.S. Vinod, and T.G. Sitharam (2010). Evaluation of Seismic Hazard Parameters for Bangalore Region in South India, Disaster Advances 3, 5-13.

Anbazhagan, P., A.Uday, , S.S.R. Moustafa and N.S.N. Al-Arifi (2016).Correlation of densities with shear wave velocities and SPT N values, J. Geophys. Eng. 13, 320-341.

Anbazhagan, P.M., Neaz Sheikh., P. Ketan Bajaj, J. MariyaDayana, H. Madhura, G.R. Reddy (2017). Empirical models for the prediction of ground motion duration for intraplate earthquakes, J. Seismolog. 21(4), 1001-1021.

Aditya, P. (2014). Seismic site classification and response studies of shallow bedrock sites, Ph.D dissertation.Indian Institute of Science, Bangalore, India.

Boominathan, A., G.R. Dodagoudar, A. Suganthi, R. Uma Maheswari (2008). Seismic hazard assessment of Chennai city considering local site effects, J. Earth Syst. Sci. 117, 853-863.

Borja, R.D., B.G. Duvernay, C.H. Lin (2002). Ground response in Lotung: Total stress analyses and parametric studies, J. Geotech. Geoenviron. 128(1), 54-63.

Capilleri, P,P., M,R. Massimino, E. Motta, M. Todaro (2018). Two-dimensional site seismic response analyses for a strategic building in Catania, Ann. Geophys. 61, 2, SE219, doi:10.4401/ag-7704.

Chandran, D and P. Anbazhagan, (2017). Subsurface profiling using integrated geophysical methods for 2D site response analysis in Bangalore city, India: a new approach, J. Geophys. Eng. 14, 1300-1314.

Cundall, P.A. (1980). NESSI - Soil structure interaction program for dynamic and static problems, Report 51508-9, Norwegian Geotechnical Institute.

Dobry, R., R.D. Borcherdt, C.B. Crouse, I.M. Idriss, W.B. Joyner, G.R. Martin, M.S. Power, E.E. Rinne, and R.B. Seed (2000). New site coefficients and site classification system used in recent building seismic code provisions, Earthquake. Spectra 16, 41-67.

Ferraro, A., S. Grasso, M.R. Massimino (2008). Site effects evaluation in Catania (Italy) by means of 1-D numerical analysis, Ann. Geophys. 61, 2, SE224, doi:10.4401/ag-7708.

Finn, W. D., E. Zhai , T,Thavaraj, X.S. Hao and C.E. Ventura (2003).1-D and 2-D analyses of weak motion data in Fraser Delta from 1966 Duvall earthquake, Soil Dyn. Earthq. Eng. 23, 323-9.

Ganesha Raj, K. and R. Nijagunappa (2004). Major Lineaments of Karnataka State and their Relation to Seismicity: Remote Sensing Based Analysis, J. Geol. Soc. India 63, 430-439.

Gawthorpe, R.L., R.E.L. Collier, J. Alexander, M. Leeder, and J.S. Bridge J.S. (1993). Ground penetrating radar: application to sand body geometry and heterogeneity studies Characterisation of Fluvial and Aeolian Reservoirs, ed C P North and D J Prosser, London: Geological Society, 73, 421-32.

Hall, W.J., B. Mohraz and N.M. Newmark, (1975). Statistical studies of vertical and horizontal earthquake spectra, Nathan M. Newmark Consulting Engineering Services, Urbana, Illinois.

Hashash, Y.M.A. and D. Park, (2001). Nonlinear one-dimensional seismic ground motion propagation in the Mississippi embayment, Eng. Geol. 62, 185-206.

Hashash, Y.M.A., D.R. Groholski, C.A. Phillips, D. Park, and M. Musgrove (2015). DEEPSOIL6.0 User Manual and Tutorial, $104 \mathrm{p}$. 


\section{Deepu Chandran et al.}

Heymsfield,E. (2000). Two-dimensional scattering of SH waves in a soil layer underlain with bedrock, Soil Dyn. Earthq.Eng. 19, 489-500.

Idriss, I. M. and Seed, H. B. (1968). Seismic response of horizontal soil layers, Soil Mech. Found. 94(4), 1003-1029.

Idriss, I. M. (1990). Response of soft soil sites during earthquakes, Proc. Symposium to Honor H. B. Seed, Berkeley, CA, 273-289.

IS 2131 (1981). Method for standard penetration test for soils Indian Standard First revision (New Delhi: Bureau of Indian Standards)

Itasca FLAC Version 7.00 (2013). A computer program for seismic response analysis for soil deposits, Tutorial and User Manual of the FLAC (Minneapolis, MN: Itasca Consulting Group).

Jaramillo A.B.A (2003). Seismological criteria for selecting and scaling real accelerograms for use in engineering analysis and design. A dissertation submitted in partial fulfillment of requirements in master degree in earthquake engineering, European School of Advanced Studies in Reduction of Seismic Risk (ROSE School).

Jaya, V. and V.R. Remmya (2010). Seismic microzonation of Thiruvananthapuram, Indian Geotechnical Conference, Mumbai, December.

Jol, H.M. and C.S. Bristow (2003). GPR in sediments: advice on data collection, basic processing and interpretation, a good practice guide Ground Penetrating Radar in Sediments, ed C S Bristow and H M Jolvol 211 (London: Geological Society), 9-27.

Kamiyama, M. and T. Satoh (2002). Seismic response analysis of laterally inhomogeneous ground with emphasis on strains, Soil Dyn. Earthq. Eng. 22, 877-84.

Khanbabazadeh, H., R. Iyisan, A. Ansal, and M.E. Hasal (2016). 2D non-linear seismic response of the Dinar basin, Turkey, Soil Dyn. Earthq. Eng. 89, 5-11.

Kramer, S.L. (1996). Geotechnical Earthquake Engineering (Prentice Hall, Upper Saddle River, New Jersey).

Kuhlemeyer, R. L. and J. Lysmer (1973). Finite element method accuracy for wave propagation problems, J. Soil Mech. \& Foundations, Div. ASCE, 99(SM5), 421-427.

Kumar, B.V.K.L., G.V.R. Rao and K.S. Rao (2012). Seismic Hazard Analysis of Low Seismic Regions, Visakhapatnam: Probabilistic Approach, J. Ind. Geophys. Union 16(1), 11-20.

Leng, Z. and I. Al-Qadi (2010). Railroad ballast evaluation using ground penetrating radar; January 10-14; laboratory investigation and field validation. Transportation Research Board 89th Annual Meeting, Washington D C, 1-15.

Leucci, G., F. Greco, L.D. Giorgi, and R. Mauceri, (2007). Three-dimensional image of seismic refraction tomography and electrical resistivity tomography survey in the castle of Occhiola (Sicily, Italy), J. Archaeol.Sci 34, 233-42

Lysmer, J. and R.L. Kuhlemeyer (1969). Finite Dynamic Model for Infinite Media, J. Eng. Mech., 95(EM4), 859-877.

Mahajan, A.K., R.J. Sporry, P.K.C. Ray, R. Ranjan, S. Slob, and W.C. Van (2007). Methodology for site-response studies using multi-channel analysis of surface wave technique in Dehradun city, Current science, 92, 945-955.

Mahajan A.K., S Chandra, V.S. Sarma and B.R. Arora (2015). Multichannel analysis of surface waves and highresolution electrical resistivity tomography in detection of subsurface features in northwest Himalaya, Curr. Sci. 108 2230-9.

Maheswari, R.U., A. Boominathan, and G.R. Dodagoudar (2008). Nonlinear Seismic Response Analysis of Selected Sites in Chennai, The 12th International Conference of International Association for Computer Methods and Advances in Geomechanics (IACMAG), 2835-2842.

Moorman, B.J., S.D. Robinson and M.M. Burgess (2003). Imaging periglacial conditions with ground-penetrating radar, Permafrost and Periglac. 14, 319-29.

Movahedasl, R. and M.R. Ghayamghamia (2015). Effects of 2D small-scale sedimentary basins on strong ground motion characteristics, J. Geophys. Eng. 12, 535-551.

Neal, A. (2004). Ground Penetrating Radar and its use in sedimentology: principles, problems and progress, EarthSci. Rev. 66, 261-330.

Panzera, F., Sicali, S., Lombardo, G., Imposa, S., Gresta, S., D’Amica, S. (2016). A microtremor survey to define the subsoil structure in a mud volcanoes area: the case study of Salinelle (Mt. Etna, Italy), Environ. Earth Sci. 75, 1140, doi:10.1007/s12665-016-5974-x.

Park, C.B., R.D. Miller, J. Xia (1999). Multichannel analysis of surface waves (MASW), Geophysics 64, 800-8.

Pellicer, X.M and P. Gibson (2011). Electrical resistivity and ground penetrating radar for the characterisation of the internal architecture of Quaternary sediments in the Midlands of Ireland, J. Appl. Geophys.75 638-47.

Phanikanth, V.S., C. Deepankar, and G.R. Reddy (2011). Equivalent-linear seismic ground response analysis of some 
typical sites in Mumbai, Geotech. Geol. Eng. 29(6), 1109-1126.

Raghukanth, S.T.G. (2011). Seismicity parameters for important urban agglomerations in India, B. Earthq. Eng. 9(5), 1361-1286.

Ramanna, C.K. and G.R. Dodagoudar (2012). Seismic Hazard Analysis using the adaptive kernel density estimation technique for Chennai City, Pure Appl. Geophys. 169(1-2), 55-69.

Rayhani, M.H.T., M.H.E. Naggar and S.H. Tabatabaei (2007). Nonlinear analysis of local site effects on seismic ground response in the bam earthquake, Geotech. Geol. Eng. 26(1), 91-100.

Roesset, J.M. (1977). Soil amplification of earthquakes, Numerical Methods in Geotechnical Engineering, C. S. Desai and J. T. Christian (ed.), McGraw-Hill, New York, pp. 649-682.

Sanchez-Sesma, F.J. and F. Luzon (1995). Seismic response of three-dimensional alluvial valleys for incident P, Sand Rayleigh waves, Bull. Seismol. Soc. Am. 85, 269-84.

Schnabel, P.B. (1973). Effects of local geology and distance from source on earthquake ground motions, Ph.D. Thesis, University of Calif., Berkeley.

Seed, H.B. and I.M. Idriss (1970). Soil moduli and damping factors for dynamic response analysis, Report No.UCB/EERC-70/10, Earthquake Engineering Research Center, University of California, Berkeley.

Semblat, J.F, Kham, E. Parara, P.Y Bard, K. Pitilakis, and K. Makra (2005). Seismic Raptakis D wave amplification: basin geometry vs soil layering. Soil Dyn. Earthq. Eng. 25, 529-38.

Shaaban F, A, Ismail, U. Massoud, H. Mesbah, A. Lethy and A.M. Abbas (2013). Geotechnical assessment of ground conditions around a tilted building in Cairo-Egypt using geophysical approaches, J. Assn Arab Univ. Basic Appl. Sci 13, 63-72.

Smith, D. G and H. M Jol (1995), Ground penetrating radar: antenna frequencies and maximum probable depths of penetration in quaternary sediments, J. Appl. Geophys, 33, 93-100.

Steeples, D.W. and R.D. Miller (1993), Basic principles and concepts of practical shallow seismic reflection profiling, Min. Eng. 45, 1297-302.

Sun, J.I., R. Golesorkhi, and H.B. Seed (1988). Dynamic moduli and damping ratios for cohesive soils, Report No. UCB/EERC-88/15, Earthquake Engineering Research Center, University of California, Berkeley.

Urbini, S., L. Vittuari and S. Gandolfi (2001). GPR and GPS data integration: examples of application in Antarctica, Ann. Geophys. 45, 687-702.

Vipin, K.S., P. Anbazhagan and T.G. Sitharam (2009). Estimation of Peak Ground acceleration and Spectral Acceleration for South India, Nat. Hazards Earth Syst. Sci. 9, European GeoSciences Union, 865-878.

Watson-Lamprey, J.A (2007). Selection and scaling of ground motion time series. A dissertation submitted in partial satisfaction of the requirements for the degree of Doctor of Philosophyin Engineering - Civil and Environmental Engineering, University of California, Berkeley.

Xia J., R.D. Miller and C.B. Park (1999). Estimation of near-surface shear-wave velocity by inversion of Rayleigh wave, Geophysics 64, 691-700.

*CORRESPONDING AUTHOR: Panjamani ANBAZHAGAN,

Associate professor, Department of Civil Engineering, Indian Institute of Science, Bangalore, India, e-mail: anbazhagan@iisc.ac.in | anbazhagan2005@gmail.com, Phone: 91-080-22932467 | Fax: 91-080-23600404 